\title{
Comparison of GPCP Monthly and Daily Precipitation Estimates with High-Latitude Gauge Observations
}

\author{
David T. Bolvin ${ }^{1,2}$, Robert F. Adler ${ }_{1,2}^{1,3}$, George J. Huffman ${ }_{4}^{1,2}$, \\ Eric J. Nelkin , Jani Poutiainen \\ 1: NASA/GSFC Laboratory for Atmospheres \\ 2: Science Systems and Applications, Inc. \\ 3: Earth System Science Interdisciplinary Center, \\ Univ. of Maryland College Park \\ 4: Finnish Meteorological Institute
}

Submitted to AMS J. Appl. Meteor. Climatol. 29 October 2008

\section{Popular Summary}

It is very important to know how much rain and snow falls around the world for uses that range from crop forecasting to disaster response, drought monitoring to flood forecasting, and weather analysis to climate research. Precipitation is usually measured with rain gauges, but rain gauges don't exist in areas that are sparsely populated, which tends to be a good portion of the globe. To overcome this, meteorologists use satellite data to estimate global precipitation. However, it is difficult to estimate rain and especially snow in cold climates using most current satellites. The satellite sensors are often "confused" by a snowy or frozen surface and therefore cannot distinguish precipitation. One commonly used satellite-based precipitation data set, the Global Precipitation Climatology Project (GPCP) data, overcomes this frozen-surface problem through the innovative use of two sources of satellite data, the Television Infrared Observation Satellite Operational Vertical Sounder (TOVS) and the Atmospheric Infrared Sounder (AIRS). Though the GPCP estimates are generally considered a very reliable source of precipitation, it has been difficult to assess the quality of these estimates in cold climates due to the lack of gauges. Recently, the Finnish Meteorological Institute (FMI) has provided a 12-year span of high-quality daily rain gauge observations, covering all of Finland, that can be used to compare with the GPCP data to determine how well the satellites estimate cold-climate precipitation.

Comparison of the monthly GPCP satellite-based estimates and the FMI gauge observations shows remarkably good agreement, with the GPCP estimates being 6\% lower in the amount of precipitation than the FMI observations. Furthermore, the month-to-month correlation between the GPCP and FMI is very high at 0.95 (1.0 is perfect). The daily GPCP estimates replicate the FMI daily occurrences of precipitation with a correlation of 0.55 in the summer and 0.45 in the winter. The winter result indicates the GPCP estimates have skill in "seeing" snowfall, which is the most challenging situation. Thus, the GPCP data set successfully overcomes a current limitation in satellite meteorology, namely the estimation of cold-climate precipitation. The success of the GPCP data set bodes well for future missions, whose instrumentation is specifically designed to give even more information for addressing cold-climate precipitation. 


\title{
Comparison of GPCP Monthly and Daily Precipitation Estimates with High-Latitude Gauge Observations
}

\author{
David T. Bolvin $^{1,2}$, Robert F. Adler , George J. Huffman ${ }_{4}^{1,2}$, \\ Eric J. Nelkin , Jani P. Poutiainen \\ 1: NASA/GSFC Laboratory for Atmospheres \\ 2: Science Systems and Applications, Inc. \\ 3: Earth System Science Interdisciplinary Center, \\ Univ. of Maryland College Park \\ 4: Finnish Meteorological Institute
}

Submitted to Journal of Applied Meteorology and Climatology

November 2008

Corresponding author:

David T. Bolvin

NASA/GSFC Code 613.1

Greenbelt, MD 20771

Phone: 301-614-6323

Fax: 301-614-5492

Email: david.t.bolvin@nasa.gov 


\begin{abstract}
The Global Precipitation Climatology Project (GPCP) produces gridded global satellite-based precipitation estimates at the monthly and daily scale. The monthly product is available at the $2.5^{\circ}$ lat./long. resolution and the daily product is produced at the $1.0^{\circ}$ lat./long. resolution. Over land, the monthly multi-satellite estimates are adjusted to the large-scale bias of and merged with the monthly Global Precipitation Climatology Centre (GPCC) gauge analyses. The monthly multi-satellite estimates over ocean and the gauge-adjusted multi-satellite estimates over land form the final GPCP satellite-gauge product. The daily product is scaled to sum to the monthly product, so it implicitly contains monthly-scale gauge influence. The monthly multi-satellite estimates, satellite-gauge estimates, and GPCC analyses, as well as the daily products, are compared to high-quality Finnish Meteorological Institute (FMI) gauge observations for the period January 1995- December 2007 to assess the quality of the GPCP estimates at high latitudes. The monthly GPCP products generally agree well with the FMI observations. The bias difference between the monthly GPCP satellite-gauge product and the FMI observations is dominated by the wind-loss adjustment applied to the GPCC analysis prior to combination with the GPCP satellite estimates. Over the entire analysis period the GPCP monthly satellite-gauge estimates are biased low by 6\% compared to the FMI observations when the same wind-loss adjustment is applied. The GPCP satellite-gauge and multi-satellite estimates replicate the time series of monthly anomalies with different degrees of fidelity, as determined by the FMI observations, with correlations of 0.9 and 0.6, respectively. This result indicates the value of using the GPCC gauge analyses over land.

The daily GPCP precipitation estimates compare reasonably well with the FMI gauge observations in the summer with a correlation of 0.55 , but less so in the winter with a correlation of 0.45. The day-to-day occurrence of precipitation is well captured by the GPCP estimates, but the corresponding precipitation event amounts tend to show wide variability. The techniques developed in this analysis, in addition to the comparison results, provide a framework for future high-latitude assessment efforts such as those that will be necessary for the Global Precipitation Measurement project.
\end{abstract}




\section{Introduction}

Knowledge of precipitation is critical to understanding climate variability, including land surface processes and the hydrologic cycle. Precipitation measurements over land typically consist of rain gauge observations that are either automated or require human monitoring. Unfortunately, in geographic areas of sparse population and/or limited resources, or over ocean, quality rain gauge observations with sufficient temporal and spatial coverage are not routinely available. To fulfill the need for globally complete precipitation information, satellite-based estimates using both infrared and microwave sensor data have been developed and are being continually refined. Microwave- and infrared-based precipitation estimates are routinely computed for the tropics and middle latitudes, but these sensors falter over cold surfaces at high latitudes. To fulfill the need for satellite-based precipitation estimates at high latitudes, other satellite data sources must be used. The Global Precipitation Climatology Project (GPCP) Version 2 (V2) monthly (Adler et al. 2003) and One-Degree Daily (1DD; Huffman et al. 2001) overcome this limitation at high latitudes (greater than $\sim 50^{\circ}$ ) through the use of Television Infrared Observation Satellite (TIROS) Operational Vertical Sounder (TOVS) sounding data, with a transition to the Atmospheric Infrared Sounder (AIRS) in April 2005. The TOVS/AIRS estimation technique infers precipitation from clouds using a regression relationship between coincident rain gauge measurements and TOVS/AIRS-based parameters, including cloud-top pressure, fractional cloud cover, and cloud-layer relative humidity (Susskind and Pfaendtner 1989; Susskind et al. 1997).

One crucial aspect of understanding and improving any satellite-based precipitation estimates is validating the results with high-quality ground-based observations. This validation work serves to show the strengths and weaknesses of the satellite-based estimates, and provides a framework for further improvement of the estimation techniques. Validation of satellite-based estimates, including GPCP, has been performed extensively in the tropics and mid-latitudes (Krajewski et al. 2000; Nicholson et al. 2003; McPhee and Margulis 2005; Gebremichael et al. 2005; Dinku et al. 2007). Some large-area validation work has also been performed at high latitudes. Adler et al. (2003) showed that the monthly GPCP V2 satellite-gauge estimates, averaged over the span 19961998, duplicated well the annual cycle of precipitation as represented by the Baltic Sea Experiment (BALTEX) gauge observations over Sweden. Skomorowski et al. (2001) compared the GPCP 1DD estimates with Mesoscale Alpine Programme (MAP) gauge observations over central alpine Europe for the period June-July 1997 and found the mean correlation was 0.57. Serreze et al. (2005) concluded that the then-current version of the monthly GPCP V2 multisatellite estimates was poorly correlated with dense gauge network observations in the Ob, Yenisey, Lena, and Mackenzie basins for all seasons except summer, for the period 1979-1993. Since then, a new version of the multi-satellite estimates, described in Section 2(a), has been introduced making obsolete the data set used in Serreze et al. (2005). Analysis results using the new corrected GPCP V2 multi-satellite estimates are presented in this paper.

Continued analysis of high-latitude precipitation is important, as estimating satellite-based precipitation at latitudes greater than $60^{\circ}$ currently presents a major challenge in computing global rainfall products. Both microwave and infrared estimates cannot differentiate between cold or icy surface and frozen precipitation. Furthermore, infrared brightness temperatures cannot discriminate precipitation in stratiform clouds that are typical at high latitudes. Though the GPCP 
the GPCP data sets, using primarily TOVS or AIRS data (hereafter referred to as TOVS/AIRS data), provide reasonable estimates of precipitation at high latitudes, their accuracy must be determined through careful comparison with ground-based observations.

Historically it has been difficult to access high-quality ground-based precipitation estimates covering the high-latitude regions for research purposes, making validation efforts challenging. To assist in these efforts, we used the Finnish Meteorological Institute (FMI) gauge data set which consists of a long record of quality-controlled, high-density rain gauge observations that measure both liquid and solid (liquid-equivalent) precipitation. Geographically and temporally, the FMI gauge data set overlaps with the Helsinki Testbed mesoscale observation network, which will be used for future satellite observation assessment activities. The spatial density of the FMI observations provides an excellent opportunity for comparison with and assessment of the GPCP estimates at the grid-box monthly and daily scale. The goal is to quantify the nature of the differences at the high latitudes to further understand the small-scale errors associated with the satellite-based GPCP estimates and provide a framework for future improvements to the estimation techniques. This framework can also serve as the basis for routine comparison and validation of high-latitude precipitation estimates from future missions such as the Global Precipitation Measurement (GPM) mission.

This paper describes the results of the comparison between the GPCP monthly/daily estimates and the FMI gauge observations. The GPCP and FMI datasets are described in section 2, and the analysis methodology is outlined in section 3. Section 4 provides the comparison results and section 5 presents the conclusions.

\section{Data Sets}

Descriptions of the GPCP and FMI datasets, used in this analysis, are provided in the following sections. Since this analysis exclusively covers latitudes greater than $60^{\circ} \mathrm{N}$, only the input data and merging techniques for the GPCP monthly and daily products at the high latitudes will be detailed here. Similarly, only the input datasets and merging techniques for the analysis span, January 1995 - December 2007, will be discussed. For details on all the input sources and complete GPCP monthly and daily global merger processes, see Adler et al. (2003) and Huffman et al. (2001), respectively.

\section{a. GPCP Monthly Estimates}

The GPCP, an international activity of the Global Energy and Water Experiment, has been tasked with developing and producing long-term, global precipitation analyses at monthly and finer time scales. The monthly product is global, has a spatial resolution of $2.5^{\circ}$ lat./long., and is available for the span January 1979 - (delayed) present. The complete monthly dataset consists of 27 precipitation and precipitation-related products, but this current analysis will focus on the multi-satellite (MS) and the satellite-gauge (SG) precipitation estimates. The GPCC gauge analyses (Rudolf 1993; Rudolf et al., 1994; Rudolf 1996), which are an input to the SG product, will also be examined in the analysis.

For the current analysis span, and for the latitudes of interest in this analysis $\left(>60^{\circ} \mathrm{N}\right)$, the MS product is computed for each month based primarily on scaled TOVS and AIRS precipitation 
estimates. The TOVS estimates span the period up to and including March 2005, with AIRS starting in April 2005 and continuing to the present. The TOVS/AIRS algorithm uses an atmospheric model (or climatology) to generate a first guess for retrieval of various atmospheric parameters, including cloud top pressure, fractional cloud cover, and relative humidity profile from NOAA-series satellite data. The precipitation algorithm is a regression between these parameters and surface data stratified by latitude, month, and land/ocean surface type (Susskind and Pfaendtner 1989; Susskind et al. 1997). The statistical nature of the TOVS/AIRS estimates suggests they are of lesser quality than corresponding SSM/I microwave estimates at lower latitudes, but are still sufficiently accurate and useful to include in precipitation combinations where present-generation high-latitude microwave estimates are unusable.

The TOVS/AIRS estimates are not used as is, but rather are scaled to higher-quality SSM/I microwave estimates in the mid-latitudes and GPCC gauge estimates at the polar latitudes. The goal is to have a spatially coherent and homogeneous precipitation field that has the presumably lower bias of the SSM/I estimates and the GPCC gauge analyses. To draw on their perceived strengths, the SSM/I and TOVS/AIRS estimates, and GPCC gauge analyses are composited in three steps to form the MS estimate. First, just north of the latitude band $37.5^{\circ} \mathrm{N}-40^{\circ} \mathrm{N}$, the SSM/I and TOVS/AIRS data are equal-weighting averaged. Second, moving further towards the pole, the SSM/I-TOVS (or SSM/I-AIRS) average is replaced with bias-adjusted TOVS/AIRS data. The bias adjustment varies linearly between the zonal average of the averaged SSM/I-TOVS (or SSM/I-AIRS) on the Equator-ward side and the zonal-average monthly GPCC rain gauge analyses on the polar side. Third, above $70^{\circ} \mathrm{N}$, TOVS/AIRS data are adjusted to the zonal-average bias of the available monthly GPCC rain gauge data. The result of these three steps is a smoothly varying "preliminary" MS precipitation field that has the large-scale bias of the SSM/I estimates in the mid-latitudes and large-scale bias of the GPCC gauge analysis in the northerly polar region, with the bulk of the adjusted estimates coming from TOVS/AIRS. After being used to compute the SG, the preliminary MS field is then adjusted to the large-scale monthly climatological bias of the SG to form the "final" MS estimate. The net effect of this last step is to add a large-scale climatological (i.e., not varying from year to year) gauge adjustment to the MS over land. This adjustment to the preliminary MS was instituted for on-going processing in July 2006, and applied retroactively to all previous MS estimates as noted above. Throughout the remainder of this paper, the final MS estimates will be referred to as MS.

The SG product is produced by first adjusting the preliminary MS estimate to the large-scale monthly GPCC gauge average for each grid box over land. Then, the gauge-adjusted preliminary MS estimate and the GPCC gauge analysis are combined in a weighted average, where the weights are the inverse (estimated) error variance of the respective estimates. It is important to note that the Legates (1987) climatological wind-loss bias correction is applied to the GPCC gauge analyses prior to combination with the preliminary MS estimate. This wind-loss correction raises the estimated GPCC gauge analysis amounts by approximately 5-400\% depending on assumed typical gauge type, surface wind speed, and precipitation fall speed. Gauge undercatch (and therefore wind-loss adjustment) is higher for frozen precipitation than for liquid precipitation. Furthermore, wind speed is the most important environmental factor contributing to the systematic undermeasurement of solid precipitation by gauges (Goodison et al., 1998). As a result, the wind-loss adjustment is largest at high latitudes and lowest in the tropics. Throughout the remainder of this paper, SG estimates will be referred to as SG. 
Examples of the SG for February 2007 and August 2007, centered on Finland, are shown in Figures 1(a) and 1(b), respectively. February shows relatively light precipitation over Finland and surrounding areas compared to August. Most noticeable in February is the low-pressure system off the west coast of Norway, where strong land-sea temperature gradients and complex terrain contribute significantly to enhanced precipitation. This effect is seen to a much lesser extent in August.

\section{b. GPCP Daily Estimates}

The GPCP responded to user-community requirements for finer scale precipitation data by commissioning production of the daily product, which has a daily temporal and $1^{\circ}$ spatial resolution, hence the name One-Degree Daily (1DD). The data spans the period from October 1996 - (delayed) present, with the GPCP day being defined as 00Z-00Z. As in the GPCP monthly product, scaled TOVS/AIRS estimates are the primary data source at high latitudes. Because of the higher temporal resolution, the scaling/merging procedure for the TOVS/AIRS must be retailored to suit the 1DD daily resolution. We briefly describe the Threshold-Match Precipitation Index (TMPI) estimates which make up the $1 \mathrm{DD}$ in the latitude band $40^{\circ} \mathrm{N}-40^{\circ} \mathrm{S}$ and form a boundary condition for the high-latitude precipitation estimates. The TMPI uses SSM/I precipitation estimates, geosynchronous IR (geo-IR) and low-earth-orbit IR (leo-IR) brightness temperatures, and the (monthly) SG product to estimate the daily precipitation. The TMPI is similar to the Geostationary Operational Environmental Satellite (GOES) Precipitation Index (GPI), but with the rain/no rain-threshold in brightness temperature set locally in space and time using the SSM/I to constrain the fractional occurrence of precipitation, and a single (local) conditional rain rate based on the (monthly) SG product to set the rain amount (Huffman et al., 2001).

Poleward of $40^{\circ} \mathrm{N}$ (and similarly in the Southern Hemisphere), at the boundary of the TMPI, the TOVS/AIRS data are scaled to provide bias-adjusted, spatially homogeneous estimates. First, the fractional coverage of the SSM/I and TOVS/AIRS must be made consistent. As the number of rain days in the TOVS/AIRS estimates is systematically high compared to the SSM/I estimates for all months and locations, the number of TOVS/AIRS rain days in a month at each grid box is reduced by computing the ratio of the zonal average number of TMPI rain days in the month to the same for TOVS/AIRS for the zonal band $39^{\circ} \mathrm{N}-40^{\circ} \mathrm{N}$. Then the number of TOVS/AIRS rain days for the month at each point in the entire hemispheric cap is scaled by the corresponding ratio. This smaller number of rain days (for that month for that grid box) is achieved by zeroing the smallest TOVS/AIRS rain accumulations. The largest daily rain amount to be zeroed is labeled as the "revised zero point." Second, the precipitation amount is determined by linearly rescaling the remaining rain days to sum to the monthly SG product. This ensures consistency between the GPCP monthly and daily products, and also has the beneficial effect of implicitly including windloss adjusted gauge "influence" into the GPCP daily product. While the resulting revised TOVS/AIRS estimates show good agreement with the TMPI, enough discrepancy remains to require smoothing at the $40^{\circ} \mathrm{N}$ data boundary. Specifically, on each day the differences between TMPI and scaled TOVS/AIRS estimates are computed for each of the $39-40^{\circ} \mathrm{N}$ latitude band grid boxes, then the difference fields are linearly tapered to zero at $50^{\circ} \mathrm{N}$ and added to the scaled TOVS/AIRS.

A time series of GPCP daily images for the period February 15-18, 2007, is shown in Figures 2(a) - (d). On February 15, precipitation from a series of typical wintertime frontal systems can 
be seen. Most noticeable is the strong low pressure system south of Iceland and west of Great Britain. On February 16, the cold front associated with this strong low is clearly visible, moving eastward and extending from the east coast of Greenland to the west coast of France and beyond. A warm front, associated with and preceding this cold front, has produced precipitation over the bulk of Finland. By February 17, the low pressure system has weakened considerably while the preceding warm front continues to propagate eastward and produce precipitation over western Russia. On February 18, the low has dissipated but the warm front still continues to produce precipitation over western Russia. The leading edge of the next low pressure system is seen south of Iceland.

\section{c. FMI Gauge Observations}

The FMI gauge observation network consists of approximately 400 reporting stations during the current period of analysis, January 1995 - December 2007. The typical geographic distribution of these stations is shown in Figure 3. In general, the gauge population is denser in southern Finland and becomes progressively sparser moving northward. The number of gauges was consistent throughout the entire analysis period with an insignificant number of station reporting gaps. In this data set, the vast majority of observations were taken using the manual Finnish H\&H-90 bucket gauge with Tretyakov wind shielding. However, approximately 30 of these manual gauges were replaced during the 2004-2007 period with automated weighing gauges (also with Tretyakov wind shielding). According to the FMI, the changeover from manual to automated gauges is not expected to affect the homogeneity of the data record. All observations are reported as daily accumulations from 06Z-06Z, and measure both liquid and solid (as liquid equivalent) precipitation. To determine the liquid equivalent, frozen precipitation is accumulated and manually melted, except at automated stations where anti-freezing liquid is used in the bucket. All gauge observations are subjected to standard and routine quality control, but no windloss adjustment is applied to the observations. The excellent quality, long homogenous record, spatial density, ability to measure frozen precipitation, and availability of the FMI gauge observations make them ideal candidates for comparison with grid-box-level satellite-based precipitation estimates. The details of the FMI station data can be found in Drebs et al. (2002). It is important to note that the 06Z-06Z FMI "day" is shifted six hours from the 00Z-00Z GPCP 1DD day. This offset will be considered when interpreting the daily results in Section 4(b).

\section{Analysis Methodology}

The GPCP monthly and daily precipitation are compared to the FMI gauge precipitation at several different spatial scales. As the GPCP precipitation estimates are gridded, the FMI gauge observations must also be gridded to the same scales for consistency. For the GPCP monthly product, which has a native $2.5^{\circ}$ lat./long. spatial resolution, all the FMI observations which lie in the corresponding $2.5^{\circ}$ lat./long. grid boxes for the month are equal-weighting averaged to form a single FMI precipitation observation.

At the daily scale, it was deemed preferable to average both the GPCP daily estimates and the FMI observations to a $1^{\circ}$ lat. $\mathrm{x} 2^{\circ}$ long. grid to obtain approximately square grid boxes (at the latitudes of Finland), which are commonly used in hydrological analyses. When gridding gauge 
observations to relatively small spatial scales, the possible uneven distribution of the gauges in a given grid box can lead to a geographical bias in the average. To overcome this, we gridded the FMI observations to the $0.25^{\circ}$ lat. $x \quad 0.5^{\circ}$ long. resolution with equal-weighting averaging. The eight $0.25^{\circ}$ lat. $\mathrm{x} 0.5^{\circ}$ long. grid box averages were then equal-weighting averaged to form the $1^{\circ}$ lat. $\mathrm{x} 2^{\circ}$ long. grid box average.

To give a sense of the FMI gauge density over the analysis area for the GPCP monthly product, the gauge population varies from 9 to 67 gauges per grid box at the $2.5^{\circ}$ resolution, with 33 being the average number of gauges per $2.5^{\circ}$ grid box. Over the GPCP daily analysis area, the gauge population varies from 13 to 25 gauges per grid box at the $1^{\circ}$ lat. $\mathrm{x} 2^{\circ}$ long. resolution, with 18 being the average number of gauges per $1^{\circ}$ lat. $\mathrm{x} 2^{\circ}$ long. grid box. The details of the geographic areas studied, in addition to the relative GPCC and FMI gauge populations, for the GPCP monthly and daily analyses are provided in Section 4.

The results of the comparisons between the monthly GPCP estimates and the FMI observations and the daily GPCP estimates and the FMI observations are presented in Sections 4(a) and 4(b), respectively.

\section{Comparison Results}

\section{a. Monthly Product}

The goal of the monthly product comparisons is to assess the long-term, large-area biases and correlations between the GPCP monthly estimates and FMI observations. Figure 3 shows the eight $2.5^{\circ}$ grid boxes (blue boxes 'A'-'H') used in the large-area monthly product comparisons. These boxes each contain a reasonable distribution of FMI gauges and minimal (ungauged) ocean surface. For reference, the average number of FMI and GPCC gauges for each of the eight $2.5^{\circ}$ grid boxes over the analysis span is shown in Table 1.

Figure 4 shows the monthly climatological averages of the SG, MS, wind-loss adjusted and unadjusted GPCC analyses, and wind-loss adjusted and unadjusted FMI observations, averaged over the 13-year span January 1995 - December 2007 and over the eight $2.5^{\circ}$ grid boxes. The annual average of each product, in $\mathrm{mm} \mathrm{day}^{-1}$, is provided in the Figure 4 legend. Note that January is duplicated after December for visual continuity. The seasonal cycle of precipitation is consistently captured by all six products, with the average precipitation rates reaching a peak in the summer and a minimum in the spring. As expected, the SG (2.01 mm day $\left.{ }^{-1}\right)$ and wind-loss adjusted GPCC (2.04 mm day ${ }^{-1}$ ) averages are nearly identical since the wind-loss adjusted GPCC estimates dominate the SG over land. The unadjusted GPCC (1.56 mm day $\left.{ }^{-1}\right)$ and FMI (1.64 mm day $^{-1}$ ) agree well in winter and spring but slightly less so in summer and fall, with the FMI being consistently higher for all months. This offset between the GPCC and FMI may be due to a number of factors. The GPCC analysis, which is based on a subset of FMI gauges over Finland, contains far fewer gauges in a $2.5^{\circ}$ grid box compared to the (complete) FMI gauge distribution as shown in Table 1. It is possible that the analysis technique used by GPCC, which uses fewer gauges and relies on gauge influence from surrounding grid boxes, tends to bias the resulting precipitation amounts low. Although it is true that in areas of complex terrain the GPCC analysis tends to underestimate precipitation, the effect is likely not important as Finland's topography is 
Finland's topography is relatively flat south of latitude $67^{\circ} \mathrm{N}$.

Because the Legates wind-loss adjustment is a single grid box multiplicative factor, the windloss adjusted GPCC (2.04 mm day ${ }^{-1}$ ) and FMI (2.14 mm day $\left.{ }^{-1}\right)$ show the same level of agreement as the unadjusted GPCC and FMI. As evidenced by the difference between the wind-loss adjusted and unadjusted GPCC (and FMI), the wind-loss adjustment follows a predictable seasonal cycle largest in the winter and smallest in the summer. The MS (2.11 mm day $\left.{ }^{-1}\right)$, which is based solely on scaled TOVS/AIRS estimates at higher latitudes, agrees well with the SG in the summer but less so in fall and winter.

The next step in the analysis is to examine how the GPCP monthly products and the FMI compare at smaller spatial scales. To show skill at smaller spatial scales, the GPCP products must be able to duplicate the interannual variability of the FMI precipitation. This is evaluated by examining the 13-year time-series of monthly precipitation anomalies for the SG and the FMI for grid box ' $E$ ' (see Figure 3). Grid box ' $E$ ' was selected as it contains a representative FMI gauge population and is centrally located in the study area. The 12 monthly climatologies for the SG and FMI are computed using all 13 years of data, and the monthly SG and FMI anomalies are computed from their corresponding climatologies. The time series of SG and FMI precipitation anomalies is shown in Figure 5. The annual average of both products, in mm day ${ }^{-1}$, is provided in the Figure 5 legend. The interannual variations in the FMI are duplicated remarkably well by the SG, showing an anomaly correlation of 0.95 over the analysis period. This high correlation indicates the value of incorporating the GPCC gauge analysis into the SG, even though that analysis is based on a relatively small number of gauges in a $2.5^{\circ}$ grid box. To assess the longterm bias of the SG relative to the FMI, the percent bias difference is defined as

$$
\% \text { Bias Diff }=\left(\left(\mathrm{GPCP}-\mathrm{FMI}_{\mathrm{WLA}}\right) / \mathrm{FMI}_{\mathrm{WLA}}\right) * 100
$$

where GPCP is the average of all the monthly GPCP (SG in this case) estimates and FMI $\mathrm{WLA}_{\mathrm{L}}$ is the average of all the wind-loss adjusted FMI observations in the analysis span. On average, the SG is biased low by 8\% compared to the wind-loss adjusted FMI for grid box ' $\mathrm{E}$ ', which is consistent with the large-area results shown in Figure 4.

Figure 6 shows the time-series of monthly anomalies for the MS product and the wind-loss adjusted FMI for grid box ' $E$ '. The annual average of both products, in mm day ${ }^{-1}$, is provided in the Figure 6 legend. The MS anomalies are not as well correlated with the wind-loss adjusted FMI as the SG, but still reasonable at 0.67 . The MS product is biased low by $3 \%$ for grid box ' $E$ ' which is also consistent with the results shown in Figure 4. The correlation and percent bias difference for the MS are impressive, given that the MS is a satellite-only precipitation estimate that includes only monthly climatological GPCC gauge influence through a pre-computed SG bias adjustment.

As seen in Figure 5, the interannual correlation between the SG and the FMI for grid box ' $E$ ' is 0.95 while the percent bias difference is $-8 \%$. Table 2 shows the corresponding statistics for all eight $2.5^{\circ}$ grid boxes ('A'-'H'). The correlations are high and vary from 0.90 to 0.99 . The SG product is consistently biased low with respect to the FMI observations, ranging from $-0.5 \%$ to $13 \%$. These statistics are striking considering the differences between the grid box GPCC and FMI gauge populations as shown in Table 1. It is not apparent that the number of gauges in either 
either the GPCC or FMI affects the percent bias differences or correlations. It is important to note that the gauges used in the GPCC analysis are a small subset of the FMI gauge data set, and that the GPCC and FMI gauge complements do fluctuate over the analysis span but not to a level believed to significantly affect the results. It also important to understand that the GPCC analysis technique (Shepard 1968; Willmott et al. 1985) does "reach out” to neighboring grid boxes, so gauge observations in adjacent grid boxes do have some influence on the final result.

Table 3 shows the percent bias differences and correlations between the MS and FMI for all eight $2.5^{\circ}$ grid boxes ('A'-' $\mathrm{H}$ '). The MS product does not capture the month-to-month anomalies as well as the SG, but the correlations are still reasonable, ranging from 0.53 to 0.77 . The percent bias differences range from $-6 \%$ to $6 \%$, underscoring the nature of the monthly climatological SG bias adjustment. Interestingly, the range of percent bias differences is approximately the same for the SG and MS products at about 12\%. However, the MS product percent bias differences tend to be centered around zero. This is somewhat surprising, as one would expect the monthly GPCC gauge analysis in the SG would provide a truer representation of the precipitation than a monthly climatological SG adjustment in the MS. It is possible that this adjustment is somehow boosting the precipitation rates by a small margin at the latitudes of this analysis, contributing to the perceived smaller bias in the MS when compared to the FMI. Further investigation into the monthly climatological SG adjustment at the higher latitudes may be warranted to fully understand these differences. The results shown in Figure 6 and Table 3 are in stark contrast to the results found in Serreze (2005), which showed zero correlation between the MS and gauge over four large-area basins. As noted above, the MS data set available to Serreze et al. (2005), equivalent to the present "preliminary" MS (defined in Section 2(a)), lacked the consistency that the climatological adjustment now produces in the present "final" MS. Accordingly, it is not surprising that the results here differ strongly from theirs.

Figures 5 and 6 showed the correlation and percent bias difference between the SG and FMI, and the MS and FMI, respectively, for $2.5^{\circ}$ grid box ' $E$ ' for all months in the analysis span. To determine how the correlations and percent bias differences vary monthly or seasonally throughout the annual cycle, the SG, MS and FMI monthly averages were computed and composited by month of year for the grid box ' $E$ '. The climatological correlations for each month between the SG and the wind-loss adjusted FMI, and the MS and wind-loss adjusted FMI, are shown in Figure 7. Note that January is duplicated after December for visual continuity. There appears to be no monthly or seasonal bias in the SG anomaly correlations, which are 0.90 or larger. The MS anomaly correlations are lower for all months, and tend to be lowest in the winter and spring and highest in the summer and fall. Other $2.5^{\circ}$ grid boxes also show consistently high SG correlations throughout the year, with no discernable annual cycle and a lower bound of 0.90 . The MS correlations tend to be low in the winter and spring but exhibit high variability from grid box to grid box. Overall, the summer and fall correlations tend to be higher, with minimal grid box-to-grid box variation. This leads to the conclusion that the GPCP highlatitude satellite sources, TOVS or AIRS, or techniques perform worse in the winter and spring than summer and fall.

Figure 8 shows the monthly climatological percent bias differences between the SG and the wind-loss adjusted FMI, and the MS and wind-loss adjusted FMI for grid box ' $E$ '. The SG differences are consistently (small) negative throughout the annual cycle while the MS differences are both positive and negative, and exhibit larger variability. The MS differences are large 
large positive in March and April, large negative in late spring/early summer, and tend to zero in the fall and early winter. Examination of other $2.5^{\circ}$ grid boxes shows the SG percent bias differences are consistently negative throughout the year. The MS percent bias differences show much larger grid box-to-grid box variability, though generally the large positive differences are still seen in March and April, and the large negative differences are seen in late spring/early summer. The high variability is likely due to the nature of the climatological SG bias adjustment, which consists of a fixed set of twelve monthly, spatially varying multiplicative ratio fields.

The monthly GPCP MS and SG product analysis results over Finland indicate that the SG is superior to the MS even in areas of low gauge coverage and should be the product of choice for the study of any interannual (or longer) variations. In areas largely lacking gauge coverage, such as oceanic regions and remote land areas, the SG is equivalent to the MS, so the MS results shown here should provide a lower bound of SG quality in such regions.

\section{b. Daily Product}

The goal of the daily product comparisons is to quantify the relationship between the GPCP estimates and FMI observations at smaller spatial and temporal scales, and to assess the skill of the GPCP estimates in capturing day-to-day precipitation events as reflected in the FMI observations. For consistency, the FMI gauge observations and GPCP daily estimates are gridded to the same $1^{\circ}$ lat. $\mathrm{x} 2^{\circ}$ long. resolution as described in Section 3 . Figure 3 shows the eight $1^{\circ}$ lat. $\mathrm{x} 2^{\circ}$ long. grid boxes (red boxes ' 1 '-‘ 8 ') used in the daily product comparisons. In parallel with the blue $2.5^{\circ}$ grid boxes, this area was selected as it contains a homogeneous distribution of FMI gauges and minimizes the amount of sea surface. The daily analysis will focus on two months, August 2005 and February 2006, which provide a representative summer and winter month, respectively.

Figure 9(a) shows a scatter plot of daily GPCP versus FMI for all $1^{\circ}$ lat. x $2^{\circ}$ long. grid box precipitation estimates from boxes ' 1 '- ‘ 8 ' for August 2005. The daily GPCP estimates are well correlated at 0.60 , but biased low by $12 \%$. The GPCP tends to underestimate precipitation at lower rates and overestimate precipitation at higher rates, as shown by the probability density function (PDF; thick line). Figure 9(b) shows the same scatter plot, but using the wind-loss adjusted FMI. Though the wind-loss adjustment is smallest in summer, the GPCP estimates are further biased low at 19\%. It is possible that the bias shift from $12 \%$ to $19 \%$ may simply be the result of the limitations of the wind-loss adjustment rather than a real effect. Regardless, it is reasonable to conclude that the August GPCP has a negative bias compared to the FMI. Furthermore, there is minimal change in the shape of the PDF. Since the wind-loss adjustment is a multiplicative factor, the correlation is unchanged. It is important to note that the original Legates wind-loss adjustment is provided and used at the $2.5^{\circ}$ resolution, so this adjustment had to be bi-linearly interpolated to the $1^{\circ}$ lat. $\mathrm{x} 2^{\circ}$ long. resolution for use with the daily FMI. As the original $2.5^{\circ}$ wind-loss adjustment does vary smoothly from grid box-to-grid box, it is believed that no major artifacts are introduced during interpolation.

Figure 10(a) shows the GPCP and FMI daily scatter plot for February 2006. Note the scales on the y-axis are different for Figures 9(a) and 10(a). The GPCP estimates are slightly less correlated at 0.52 , but are biased high by $89 \%$. Only at very low rates is GPCP underestimating the 
the precipitation. Figure 10(b) shows the GPCP and wind-loss adjusted FMI scatter plot. The bias in the GPCP is greatly reduced to $10 \%$ high. The wind-loss adjustment reaches a maximum in February, which accounts for the noticeable improvement. It is clear from the scatter plot that the wind-loss adjustment is necessary. This wind-loss adjustment is implicitly included in the GPCP daily estimates through scaling with the monthly SG product, which explicitly includes the wind-loss adjusted GPCC gauge analysis. Examination of the same analysis area for other months reveals the same general shape in the PDFs - GPCP underestimates precipitation at the lowest rates (below $1 \mathrm{~mm} \mathrm{day}^{-1}$ ) and overestimates precipitation at higher rates. This is also seen, to some degree, for the individual $1^{\circ}$ lat. $\mathrm{x} 2^{\circ}$ long. grid box scatter plots, though the variability is much higher due to the small number of points. The underestimation by GPCP at the low end is likely due to the spatial and temporal mismatch of large-footprint satellite precipitation estimates and point gauge observations. A dense network of gauges may be more likely to measure small areas of precipitation that occur within a grid box. In contrast, the footprint size of the satellite pixel (typically measured in kilometers) may tend to alias areas of small precipitation due to detectability issues. This underestimation is more significant in August, when smaller convective cells are more dominant. In February, synoptic-scale systems dominate so there is less chance of underestimation of precipitation by the satellite.

To assess the skill of the GPCP daily product in duplicating the day-to-day occurrences of precipitation, it is useful to show time-series of daily precipitation values for a given $1^{\circ}$ lat. $\mathrm{x} 2^{\circ}$ long. grid box. Figure 11(a) shows the daily time series of precipitation for the GPCP, FMI, and wind-loss adjusted FMI for August 2005 for box ' 5 ' shown in Figure 3. Though there is considerable variability from grid box to grid box in the time series, box ' 5 ' is representative of typical behavior. In general, GPCP sees the same events as the FMI with a correlation of 0.69. There are noticeable exceptions in the time series where the GPCP and FMI occurrences appear to be offset by one day, such as August 6 and 7. This is likely the result in the difference in the definition of a day. The GPCP day spans 00Z-00Z, while the FMI gauge accumulations span 06Z-06Z. If significant precipitation occurs within this six-hour time difference, the amount will be attributed to different days for the GPCP and FMI. This will result in an apparent lag or lead in the GPCP precipitation occurrence and affect the amount of precipitation ascribed to adjacent days. Note that the wind-loss adjustment barely changes the FMI precipitation amounts for August. The percent bias difference between the GPCP and wind-loss adjusted FMI for box ' 5 ' is $-3 \%$, which is consistent with the results shown in Figure 9(b). Figure 11(b) shows the box ' 5 ' time series plot for February 2006. Note the scales on the y-axis are different for Figures 11(a) and 11(b). The precipitation correlates reasonably well at 0.50 , but the GPCP tends to overestimate the precipitation amount, even when the wind-loss adjustment, which is a maximum in February, is applied to the FMI precipitation. This behavior is also observed, to some extent, in the other red grid boxes, and is, in part, likely due to the difficulty of estimating frozen precipitation using satellite observations. The percent bias difference between the GPCP and wind-loss adjusted FMI for box ' 5 ' is $25 \%$, which is consistent with the results shown in Figure 10(b).

It is well known that spatial and temporal averaging of precipitation will reduce noise and increase cross correlation (Bell et al., 1990). To quantify the effect of averaging on the correlation between the GPCP and FMI, we consider a $4^{\circ}$ lat. $\mathrm{x} 4^{\circ}$ long. "master” grid box, $60^{\circ} \mathrm{N}$ $64^{\circ} \mathrm{N}$ and $24^{\circ} \mathrm{E}-28^{\circ} \mathrm{E}$ (encompassing all eight grid boxes ' 1 '- ' 8 '), and compute correlations for 
for progressively larger spatial scales and progressively longer temporal scales. For this computation, data from all 13 Augusts and all 13 Februaries in the analysis span were used. To isolate the effect of spatial averaging, GPCP and FMI correlations are computed separately for all $1^{\circ}$ lat. $\mathrm{x} 1^{\circ}$ long., $1^{\circ}$ lat. $\mathrm{x} 2^{\circ}$ long., and $2^{\circ}$ lat. $\mathrm{x} 2^{\circ}$ long. grid boxes that fall within the $4^{\circ}$ lat. $\mathrm{x} 4^{\circ}$ long. "master" grid box for all Augusts and all Februaries. The result of this computation is shown in Figure 12(a). For both August and February, the correlation increases with progressively larger spatial resolution. August shows a more pronounced improvement, from 0.5 to 0.7, than February. At all spatial scales, the GPCP and FMI are more highly correlated in August than February. It is important to note the correlations in Figure 12(a) are for the $1^{\circ}$ lat. $\mathrm{x}$ $2^{\circ}$ long. spatial averaging scale. These values, 0.55 for August and 0.45 for February, show that the correlations for the August 2005 and February 2006 results, shown in Figures 9(a) and 10(a), are consistent with the long-term average correlations.

To isolate the effect of temporal averaging, GPCP and FMI correlations are computed for all $1^{\circ}$ lat. $\mathrm{x} 2^{\circ}$ long. grid boxes (within the $4^{\circ}$ lat. $\mathrm{x} 4^{\circ}$ long. "master" grid box) averaged in time to one day, three days, six days, 10 days, and 30 days. The "30-day" average for February only contains 28 or 29 days. The results are shown in Figure 12(b). The GPCP and FMI correlations increase for progressively increasing averaging time scale. As in Figure 12(a), the correlations for August are consistently higher than the correlations for February, with the 30-day averaging period being the notable exception. As concluded in previous studies (Bell et al., 1990), temporal averaging increases correlations at a faster rate than spatial averaging.

\section{Conclusions and Future Work}

The goal of this analysis was to compare the GPCP monthly and daily products at highlatitudes with high-quality, high-density FMI gauge observations to assess the quality of the GPCP estimates. The monthly product results show the large-area, long-term average SG duplicates the mean annual cycle of precipitation as observed by the FMI. The difference between the SG and FMI is dominated by the Legates wind-loss adjustment applied to the GPCC gauge analysis, which is heavily weighted in the SG over land. For the analysis period, the SG is biased low by $6 \%$ when compared to the wind-loss adjusted FMI. The small low bias of the SG is likely due to the GPCC analysis scheme, which draws upon a lower gauge population and includes influence from gauges in surrounding grid boxes. Despite the radical differences in the GPCC and FMI gauge populations, the comparison results are a testament to the overall quality of the GPCC gauge analyses when compared to dense gauge observations. These results reveal that the technique chosen for incorporating the GPCC gauge analysis into the SG, implemented in GPCP Version 1 in the mid-1990s, was a judicious design choice. Like the SG, the MS also reasonably duplicates the annual cycle of FMI precipitation despite only having climatological gauge influence.

The SG and MS both capture the long-term interannual variability of precipitation as determined by the FMI. The correlation in the monthly SG anomalies is high at 0.90 or greater for all months of the year while the percent bias difference is consistently small and negative. The MS anomalies are less correlated at 0.53 or higher for all months of the year. However, MS is better correlated in the summer and fall than the winter and spring, where there exists large 
variability from grid box to grid box. In areas largely lacking gauge coverage, the SG is equivalent to the MS, so the MS quality should provide a lower bound of SG quality.

The daily GPCP and FMI precipitation are well correlated at 0.55 for August (summer) and at a lower level, 0.45, for February (winter). These results are consistent with daily results in other studies, including BALTEX in Huffman et al (2001). The differences between the daily GPCP and FMI can be due to a number of factors, including using a wind-loss adjustment developed on assumptions inconsistent with the FMI gauge type, interpolation of the wind-loss adjustment from $2.5^{\circ}$ degrees, differences in the definition of the FMI day and the GPCP day, issues with the applicability of a monthly wind-loss correction applied to the FMI at the daily scale (i.e., changes in relative frequency of snow and windiness), and assumptions concerning the rescaling of the frequency of TOVS/AIRS precipitation at the latitudes of Finland based on the precipitation frequency at $40^{\circ} \mathrm{N}$ latitude (see Section 2 (b)). The daily product comparison results also show the GPCP estimates are consistently biased low at low precipitation rates, likely the result of satellite detectability issues associated with light or small areas of precipitation or short-lived events being missed. Using the daily data, it was shown that spatial and temporal averaging improves the GPCP and FMI correlations.

The monthly comparison results show that the GPCC gauge analysis is the primary factor in determining the level of agreement between the SG and FMI since the GPCC analysis is heavily weighted over land in the SG. Several improvements to the GPCC gauge analysis have been recently implemented, and are currently under consideration for use in GPCP. First, GPCC has introduced a new climatology-anomaly-based gauge analysis technique, which is designed to improve accuracy, especially over complex terrain (Udo Schneider, personal communication). This better gauge analysis will likely be implemented in the next version of the GPCP data set, as it is available for the entire GPCP span January 1979 - present. Second, beginning in January 2007, an event-specific, gauge-by-gauge wind-loss adjustment is being distributed as part of the GPCC analyses. GPCP is still investigating how best to incorporate this significantly more accurate wind-loss adjustment. GPCP is also investigating the wind-loss adjustments developed by Yang et al. (2005), which hold promise considering the long record available in his data set.

The skill of the daily GPCP estimates at duplicating the FMI precipitation (both liquid and solid) is quite promising, considering that the GPCP estimates at high latitudes are based primarily on statistically derived TOVS/AIRS satellite data. Further analysis needs to be performed to understand and minimize the day-to-day differences in the precipitation amounts. The success of the GPCP products at replicating the FMI precipitation at high latitudes provides strong support for pursuing future high-resolution GPM-era precipitation estimates. The analysis techniques developed here will also provide a framework from which routine comparison and assessment of GPM-era satellite estimates and rain gauge observations can be performed.

\section{Acknowledgements}

The authors acknowledge and thank the Finnish Meteorological Institute for providing the highquality Finnish gauge dataset used in this work. The authors also acknowledge the support of Dr. W. Scott Curtis for help in generating several figures. 


\section{References}

Adler, R.F., G.J. Huffman, A. Chang, R. Ferraro, P. Xie, J.E. Janowiak, B. Rudolf, U. Schneider, S. Curtis, D.T. Bolvin, A. Gruber, J. Susskind, P.A. Arkin, and E.J. Nelkin, 2003: The Version 2 Global Precipitation Climatology Project (GPCP) Monthly Precipitation Analysis (1979Present). J. Hydrometeor., 4, 1147-1167.

Bell, T.L., A. Abdullah, R.L. Martin, and G.R. North, 1990: Sampling Errors for Satellite-Derived Tropical Rainfall: Monte Carlo Study Using a Space-Time Stochastic Model. J. Geophys. Res., 95, 2195-2205.

Dinku T, P. Ceccato, E. Grover-Kopec, et al., 2007: Validation of satellite rainfall products over East Africa's complex topography, Internat. J. Rem. Sens., 28, 1503-1526.

Drebs, A., A. Nordlund, P. Karlsson, J. Helminen, and P. Rissanen, 2002: Climatological statistics of Finland 1971-2000. Climatic statistics of Finland 2002, Finnish Meteorological Institute, $97 \mathrm{pp}$.

Gebremichael M., W.F. Krajewski, M.L. Morrissey, et al., 2005: A Detailed Evaluation of GPCP $1^{\circ}$ Daily Rainfall Estimates over the Mississippi River Basin, J. Appl. Meteor., 44, 665-681.

Goodison, B. E., P. Y. T. Louie, and D. Yang, 1998: WMO solid precipitation measurement intercomparison. Final report. Instruments and Observing Methods, 67, WMO/TD 872. World Meteorological Organization.

Huffman, G.J., R.F. Adler, M. Morrissey, D.T. Bolvin, S. Curtis, R. Joyce, B McGavock, J. Susskind, 2001: Global Precipitation at One-Degree Daily Resolution from Multi-Satellite Observations. J. Hydrometeor., 2, 36-50.

Krajewski W.F., G.J. Ciach, J.R. McCollum, and C. Bacoti, 2000: Initial Validation of the Global Precipitation Climatology Project Monthly Rainfall over the United States, J. Appl. Meteor., 39, 1071-1086.

Legates, D. R., 1987: A Climatology of Global Precipitation. Publications in Climatology, Vol. 40, University of Delaware, 85 pp.

McPhee J., and S.A. Margulis, 2005: Validation and error characterization of the GPCP-1DD precipitation product over the contiguous United States, J. Hydrometeor., 6, 441-459.

Nicholson S.E., B. Some, J. McCollum, et al., 2003: Validation of TRMM and other rainfall estimates with a high-density gauge dataset for West Africa. Part I: Validation of GPCC rainfall product and pre-TRMM satellite and blended products, J. Appl. Meteor., 42, 13371354.

Rudolf, B., 1993: Management and analysis of precipitation data on a routine basis. Proc. Int. WMO/IAHS/ETH Symp. on Precipitation and Evaporation, M. Lapin, and B. Sevruk, Eds., Bratislava, Slovak Hydrometeor. Inst., 1, 69-76.

Rudolf, B., H. Hauschild, W. Rueth, and U. Schneider, 1994: Terrestrial precipitation analysis: operational method and required density of point measurements. Global Precipitation and Climate Change, NATO ASI Series, 1(26), 173-186, M. Desbois and F. Desalmand, Eds., Springer-Verlag.

Rudolf, B., 1996: Global Precipitation Climatology Centre activities. GEWEX News, 6(1).

Serreze, M.C., A.P. Barrett, and F. Lo, 2005: Northern High-Latitude Precipitation as Depicted by Atmospheric Reanalyses and Satellite Retrievals. Mon. Wea. Rev., 133, 3407-3430.

Shepard, D., 1968: A two-dimensional interpolation function for irregularly spaced data. Proc. 23rd ACM Nat'l. Conf., Princeton, NJ, Brandon/Systems Press, 517-524. 
Skomorowski, P., F. Rubel, and B. Rudolf, 2001: Verification of GPCP -1DD Global Satellite Precipitation Products Using MAP Surface Observations. Phys. Chem. Earth, 26, 403-409.

Susskind, J., and J. Pfaendter, 1989: Impact of interactive physical retrievals of NWP. Report on the Joint ECMWF/EUMETSAT Workshop on the Use of Satellite Data in Operational Weather Prediction: 1989-1993, T. Hollingsworth, Ed., Vol. 1, ECMWF, 245-270.

Susskind, J., P. Piraino, L. Rokke, T. Iredell, and A. Mehta, 1997: Characteristics of the TOVS Pathfinder Path A dataset. Bull. Amer. Meteor. Soc., 78, 1449-1472.

Willmott, C.J., C.M. Rowe, and W.D. Philpot, 1985: Small-scale climate maps: a sensitivity analysis of some common assumptions associated with grid-point interpolation and contouring. The Amer. Cartographer, 12, 5-16.

Yang, D., D. Kane, Z. Zhang, D. Legates, and B. Goodison, 2005: Bias corrections of long-term (1973-2004) daily precipitation data over the northern regions. Geophys. Res. Lett., 32, L15901, doi:10.1029/2005GL024057. 


\section{Table Legends}

1. Average number of FMI and GPCC gauges over the analysis span January 1995 - December 2007 for each of the eight blue $2.5^{\circ}$ grid boxes 'A'-' $H^{\prime}$ ' in Figure 3.

2. Correlation coefficient and percent bias difference between the monthly SG estimates and wind-loss adjusted FMI gauge observations for each of the eight blue $2.5^{\circ}$ grid boxes ' $\mathrm{A}$ '-' $\mathrm{H}$ ' in Figure 3.

3. Correlation coefficient and percent bias difference between the monthly MS estimates and wind-loss adjusted FMI gauge observations for each of the eight blue $2.5^{\circ}$ grid boxes 'A' ' $\mathrm{H}$ ' in Figure 3. 


\section{Figure Captions}

1. GPCP monthly SG precipitation estimates for an area centered around Finland for February 2007 (Fig. 1a) and August 2007 (Fig. 1b). The units of precipitation are mm day ${ }^{-1}$.

2. GPCP daily precipitation estimates for an area centered around Finland for February 15-18, 2007 (Figs. 2a-d). The units of precipitation are $\mathrm{mm} \mathrm{day}^{-1}$.

3. Example distribution of FMI gauges (red dots) over the analysis span January 1995 December 2007. Boxes 'A'-'H' (blue) show the geographical area used in the $2.5^{\circ}$ monthly analysis and boxes ' 1 '-' 8 ' (red) show the geographical area used in the $1^{\circ}$ lat. $\mathrm{x} 2^{\circ}$ long. daily analysis.

4. Time series of monthly climatological averages of the SG estimates (solid black), MS estimates (solid blue), wind-loss adjusted and unadjusted GPCC analyses (solid and dashed red, respectively), and wind-loss adjusted and unadjusted FMI observations (solid and dashed green, respectively), averaged over the 13-year span January 1995 - December 2007 and over the eight $2.5^{\circ}$ grid boxes. The annual average of each product, in $\mathrm{mm} \mathrm{day}^{-1}$, is provided in the legend. January is duplicated after December for visual continuity.

5. Time series of monthly SG (black) and FMI (red) precipitation anomalies for $2.5^{\circ}$ grid box ' $E$ ' over the entire analysis span January 1995 - December 2007. The annual average of both products, in mm day ${ }^{-1}$, is provided in the legend.

6. Time series of monthly MS (black) and FMI (red) precipitation anomalies for $2.5^{\circ}$ grid box 'E' over the entire analysis span January 1995 - December 2007. The annual average of both products, in $\mathrm{mm} \mathrm{day}^{-1}$, is provided in the legend.

7. Time series of monthly climatological correlation coefficients between the monthly SG estimates and the wind-loss adjusted FMI gauge observations (solid line), and the monthly MS estimates and wind-loss adjusted FMI gauge observations (dashed line) for $2.5^{\circ}$ grid box ' $\mathrm{E}$ '. January is duplicated after December for visual continuity.

8. Time series of monthly climatological percent bias difference between the monthly SG estimates and the wind-loss adjusted FMI gauge observations (solid line), and the monthly MS estimates and wind-loss adjusted FMI gauge observations (dashed line) for $2.5^{\circ}$ grid box ' $E$ '. January is duplicated after December for visual continuity.

9. Scatter plot of all daily $1^{\circ}$ lat. $\times 2^{\circ}$ long. grid box GPCP precipitation estimates and FMI gauge observations, and GPCP estimates and wind-loss adjusted FMI gauge observations from boxes '1'-'8' for August 2005 (Figs. 9a and 9b, respectively). The PDF for each scatter plot is provided (thick line).

10. Scatter plot of all daily $1^{\circ}$ lat. x $2^{\circ}$ long. grid box GPCP precipitation estimates and FMI gauge observations, and GPCP estimates and wind-loss adjusted FMI gauge observations from boxes '1'-‘ 8 ' for February 2006 (Figs. 10a and 10b, respectively). The PDF for each scatter plot is provided (thick line).

11. Time series of daily precipitation of the GPCP (black), FMI (red), and wind-loss adjusted FMI (green) precipitation for August 2005 (Fig 11a) and February 2006 (Fig. 11b) for $1^{\circ}$ lat. x $2^{\circ}$ long. grid box ' 5 '.

12. Correlation coefficient between the daily GPCP and FMI precipitation as a function of spatial averaging grid box size using all Augusts (black) and all Februaries (red) in the entire analysis span 1995 - 2007 (Fig. 12a), and correlation coefficient as a function of time averaging for all Augusts (solid line) and all Februaries (dashed line) using all $1^{\circ}$ lat. x $2^{\circ}$ long. grid boxes ' 1 '‘8' (Fig. 12b). 
Table 1. Average number of FMI and GPCC gauges over the analysis span January 1995 December 2007 for each of the eight blue $2.5^{\circ}$ grid boxes 'A'-' $\mathrm{H}^{\prime}$ in Figure 3.

\begin{tabular}{|c|c|c|}
\hline Box & $\begin{array}{c}\text { Average \# of FMI } \\
\text { Gauges }\end{array}$ & $\begin{array}{c}\text { Average \# of } \\
\text { GPCC Gauges }\end{array}$ \\
\hline A & 12 & 2 \\
\hline B & 9 & 1 \\
\hline C & 16 & 3 \\
\hline D & 22 & 2 \\
\hline E & 42 & 2 \\
\hline F & 34 & 4 \\
\hline G & 63 & 5 \\
\hline H & 67 & 6 \\
\hline
\end{tabular}

Table 2. Correlation coefficient and percent bias difference between the monthly SG estimates and wind-loss adjusted FMI gauge observations for each of the eight blue $2.5^{\circ}$ grid boxes 'A'-' $\mathrm{H}$ ' in Figure 3.

\begin{tabular}{|c|c|c|}
\hline Box & Correlation Coefficient & Percent Bias Difference (\%) \\
\hline A & 0.96 & -3 \\
\hline B & 0.90 & -6 \\
\hline C & 0.94 & -6 \\
\hline D & 0.95 & -3 \\
\hline E & 0.95 & -8 \\
\hline F & 0.97 & -13 \\
\hline G & 0.99 & -5 \\
\hline H & 0.97 & -0.5 \\
\hline
\end{tabular}

Table 3. Correlation coefficient and percent bias difference between the monthly MS estimates and wind-loss adjusted FMI gauge observations for each of the eight blue $2.5^{\circ}$ grid boxes 'A'-' $\mathrm{H}^{\text {' }}$ in Figure 3.

\begin{tabular}{|c|c|c|}
\hline Box & Correlation Coefficient & Percent Bias Difference (\%) \\
\hline A & 0.56 & 1 \\
\hline B & 0.54 & -0.4 \\
\hline C & 0.53 & -3 \\
\hline D & 0.62 & 0.2 \\
\hline E & 0.67 & -3 \\
\hline F & 0.67 & -6 \\
\hline G & 0.77 & -4 \\
\hline H & 0.68 & 6 \\
\hline
\end{tabular}




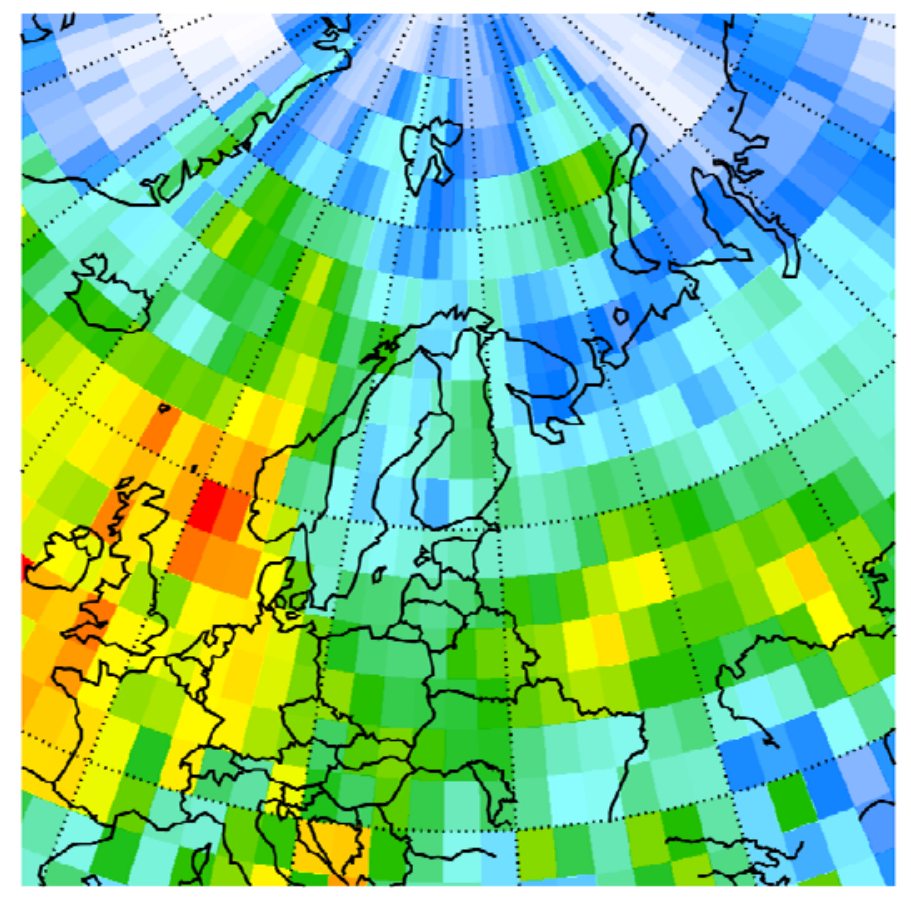

$\mathrm{mm} /$ doy

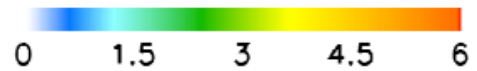

(a)

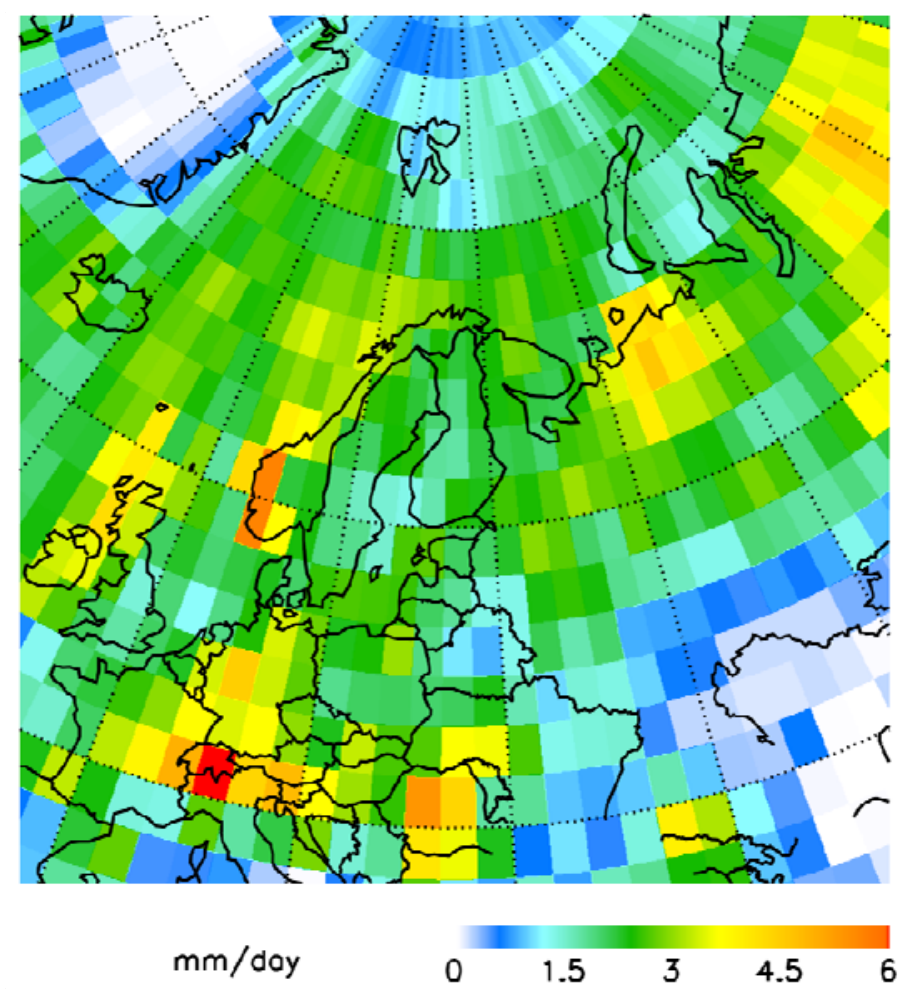

(b)

Fig 1. GPCP monthly SG precipitation estimates for an area centered around Finland for February 2007 (Fig. 1a) and August 2007 (Fig. 1b). The units of precipitation are $\mathrm{mm} \mathrm{day}^{-1}$. 


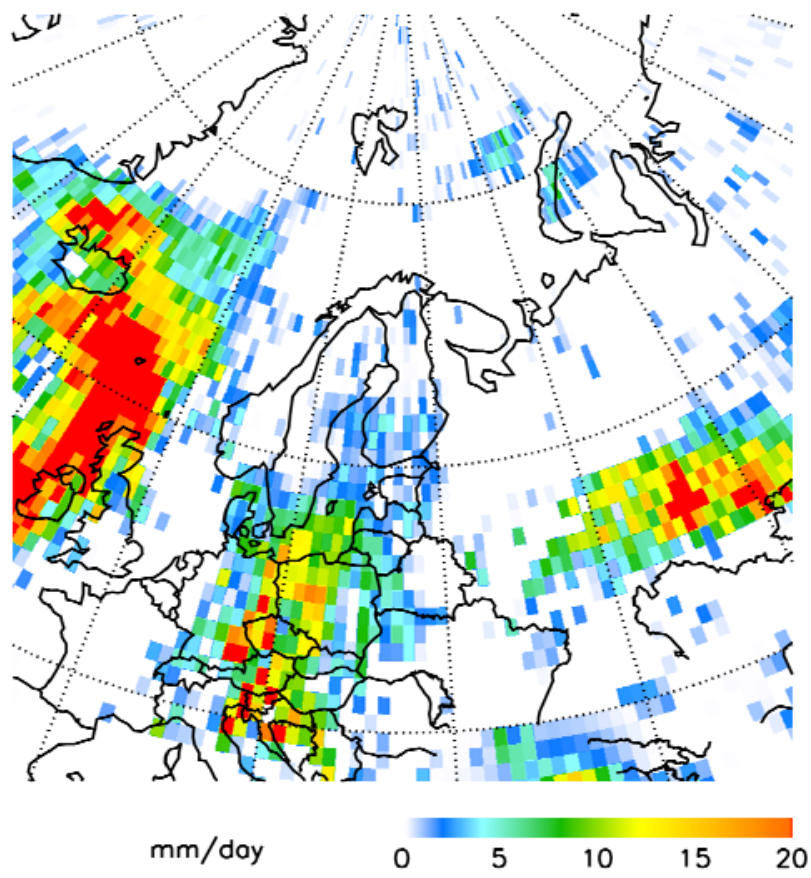

(a)

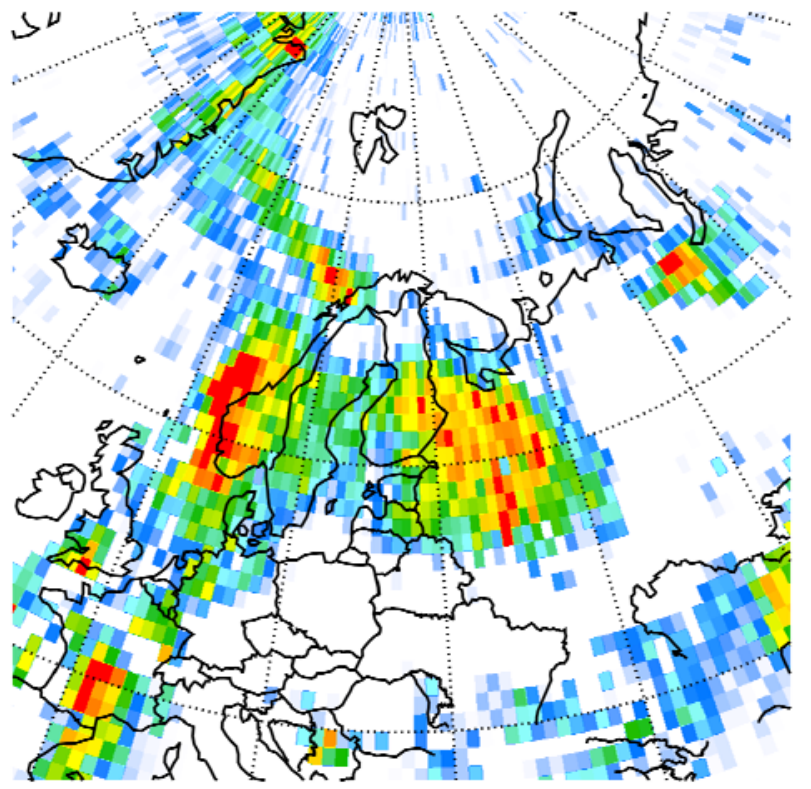

$\mathrm{mm} /$ day

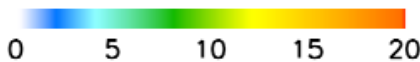

(c)

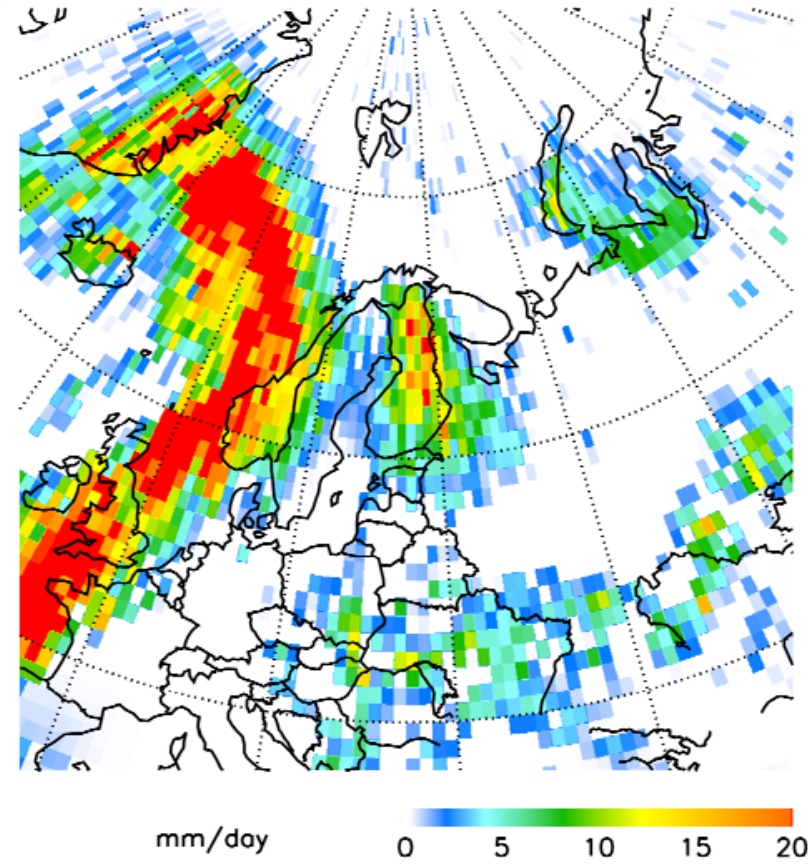

(b)

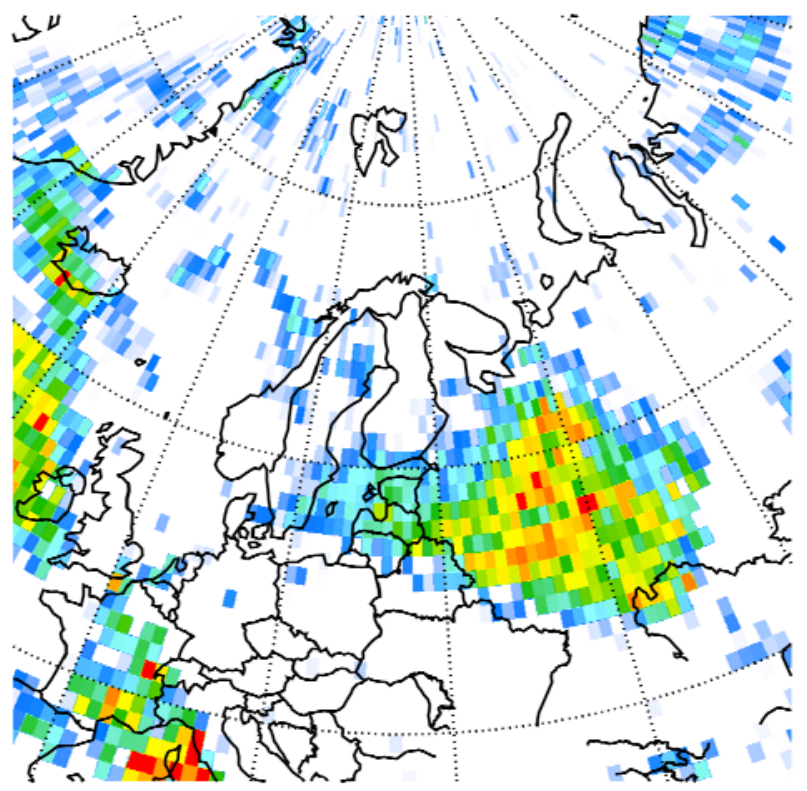

$\mathrm{mm} /$ day

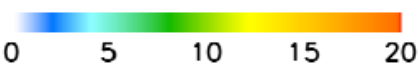

(d)

Fig. 2. GPCP daily precipitation estimates for an area centered around Finland for February 15-18, 2007 (Figs. 2a-d). The units of precipitation are $\mathrm{mm} \mathrm{day}^{-1}$. 


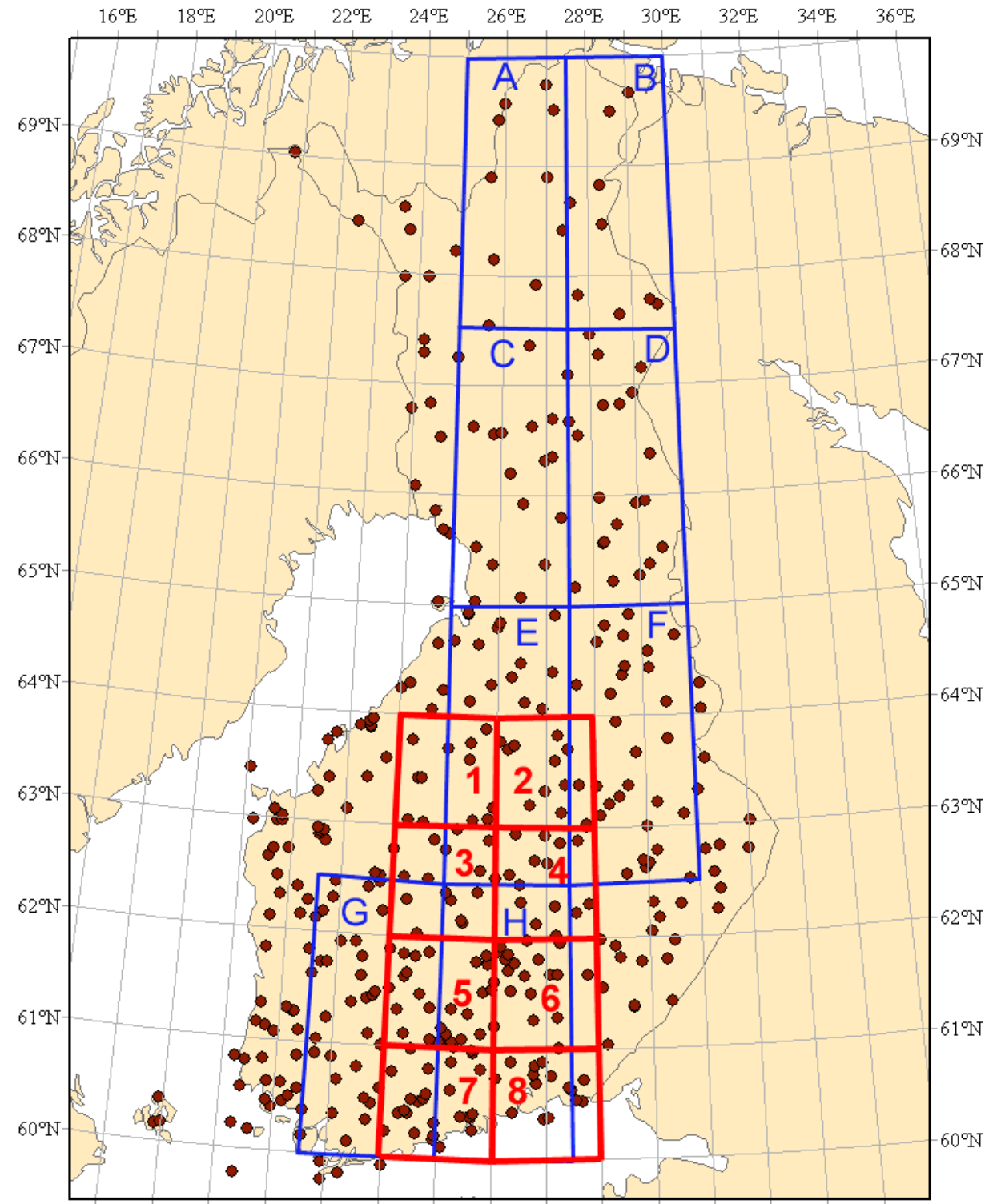

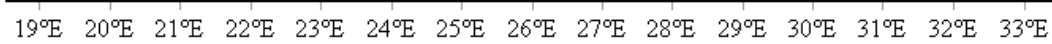

Fig 3. Example distribution of FMI gauges (red dots) over the analysis span January 1995 - December 2007. Boxes 'A'-'H' (blue) show the geographical area used in the $2.5^{\circ}$ monthly analysis and boxes ' 1 '-' 8 ' (red) show the geographical area used in the $1^{\circ}$ lat. $\mathrm{x} 2^{\circ}$ long. daily analysis. 


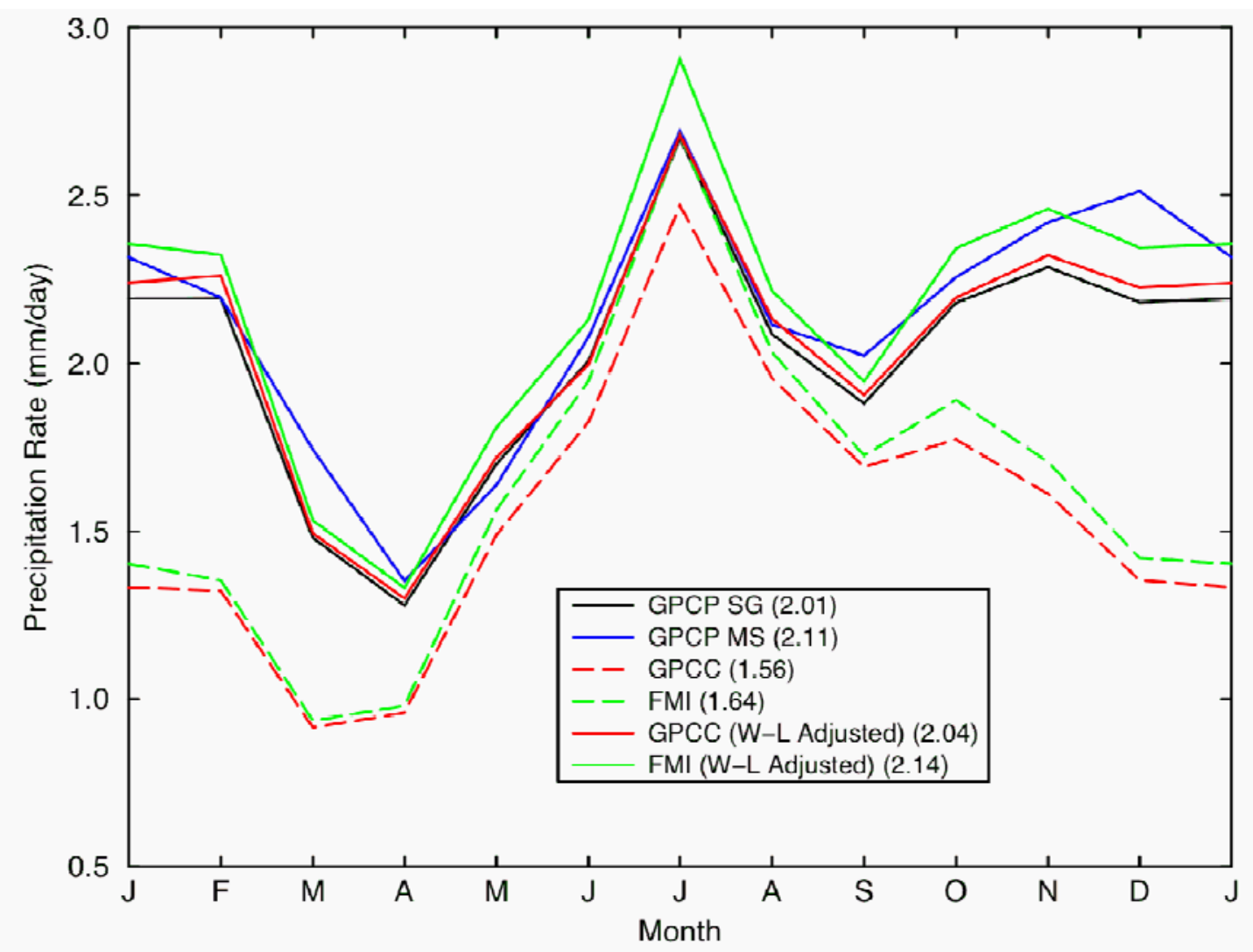

Fig 4. Time series of monthly climatological averages of the SG estimates (solid black), MS estimates (solid blue), wind-loss adjusted and unadjusted GPCC analyses (solid and dashed red, respectively), and wind-loss adjusted and unadjusted FMI observations (solid and dashed green, respectively), averaged over the 13-year span January 1995 December 2007 and over the eight $2.5^{\circ}$ grid boxes. The annual average of each product, in mm day ${ }^{-1}$, is provided in the legend. January is duplicated after December for visual continuity. 


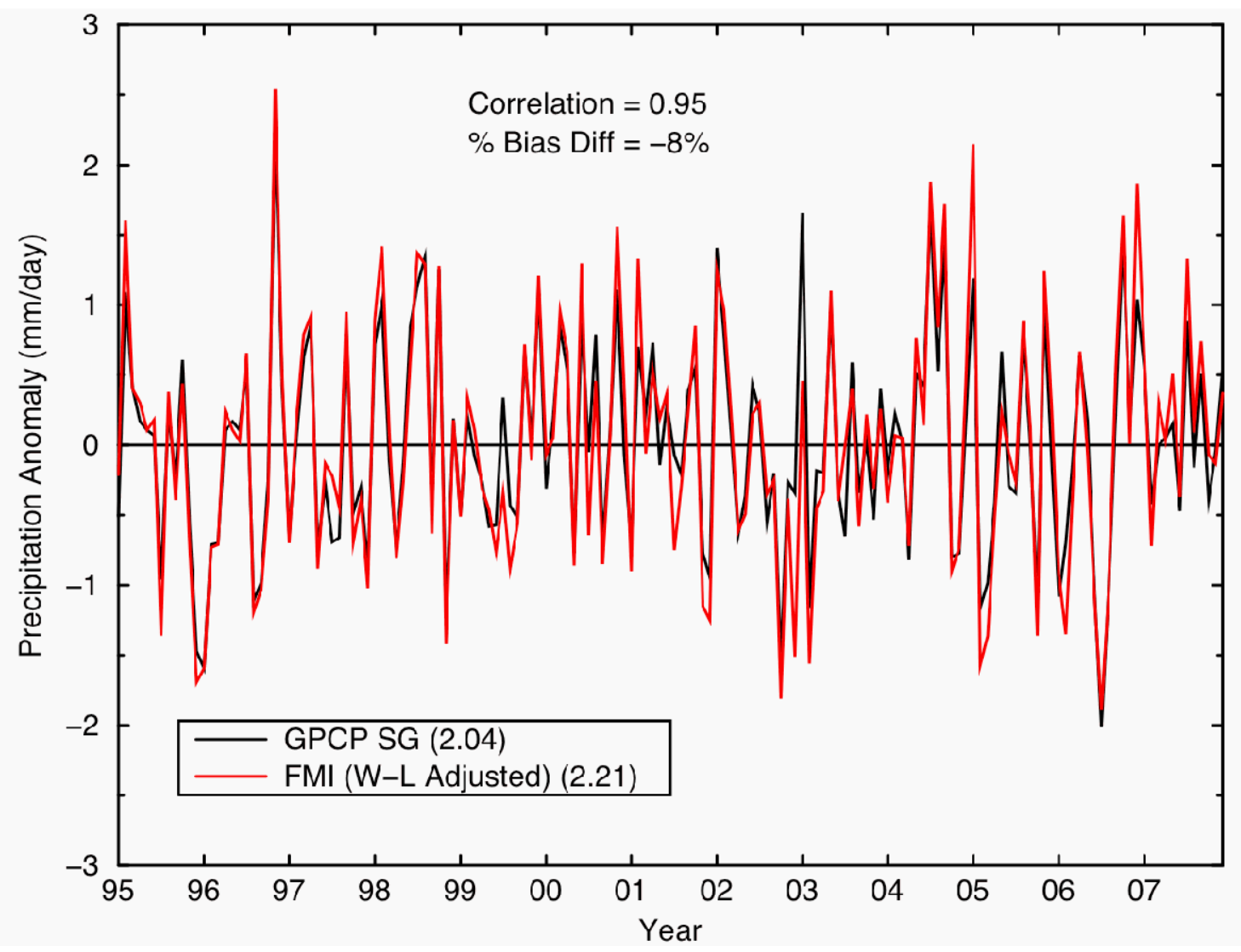

Fig 5. Time series of monthly SG (black) and FMI (red) precipitation anomalies for $2.5^{\circ}$ grid box 'E' over the entire analysis span January 1995 December 2007. The annual average of both products, in $\mathrm{mm} \mathrm{day}^{-1}$, is provided in the legend. 


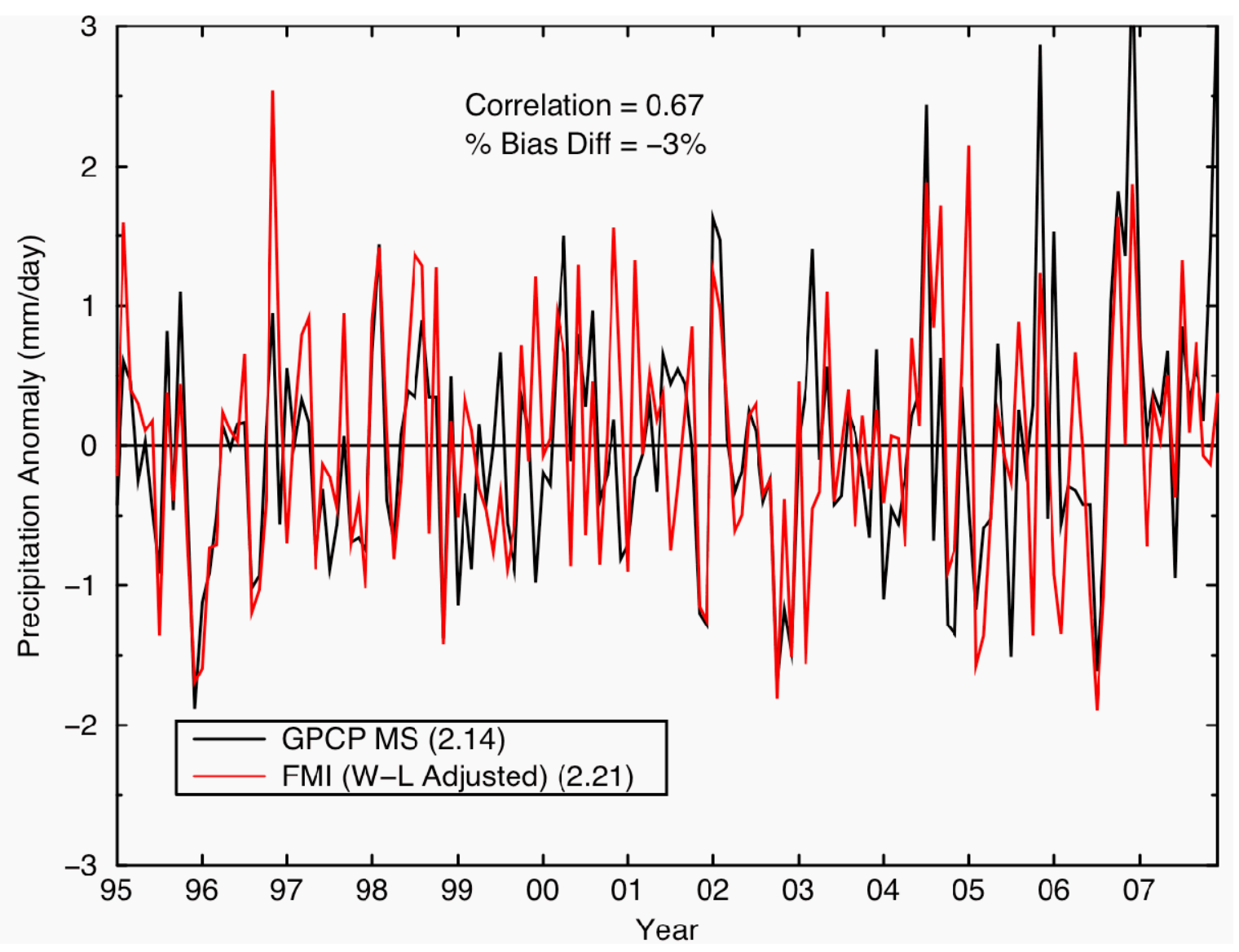

Fig 6. Time series of monthly MS (black) and FMI (red) precipitation anomalies for $2.5^{\circ}$ grid box ' $E$ ' over the entire analysis span January $1995-$ December 2007. The annual average of both products, in $\mathrm{mm} \mathrm{day}^{-1}$, is provided in the legend. 


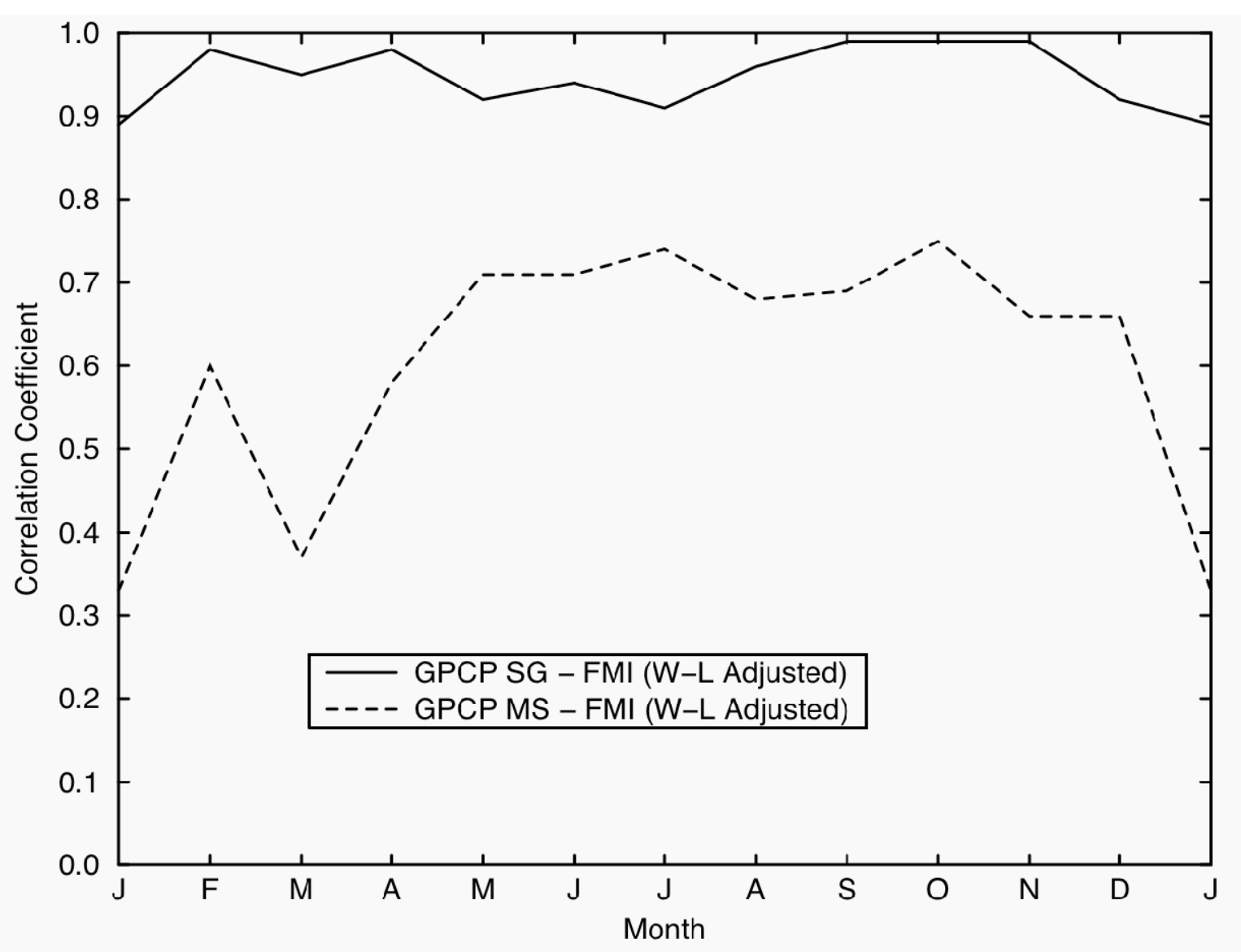

Fig 7. Time series of monthly climatological correlation coefficients between the monthly SG estimates and the wind-loss adjusted FMI gauge observations (solid line), and the monthly MS estimates and wind-loss adjusted FMI gauge observations (dashed line) for $2.5^{\circ}$ grid box 'E'. January is duplicated after December for visual continuity. 


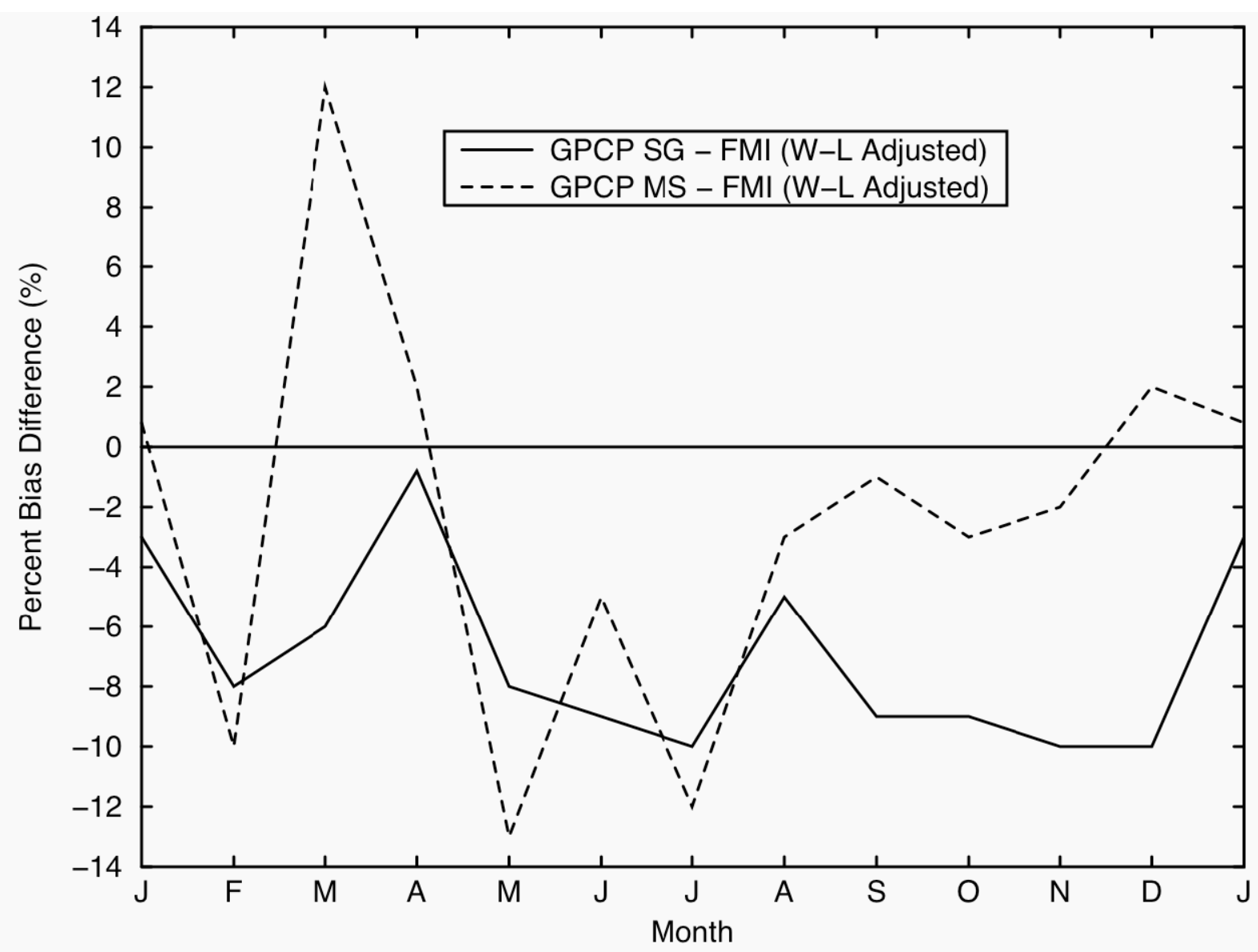

Fig 8. Time series of monthly climatological percent bias difference between the monthly SG estimates and the wind-loss adjusted FMI gauge observations (solid line), and the monthly MS estimates and wind-loss adjusted FMI gauge observations (dashed line) for $2.5^{\circ}$ grid box ' $\mathrm{E}$ '. January is duplicated after December for visual continuity. 


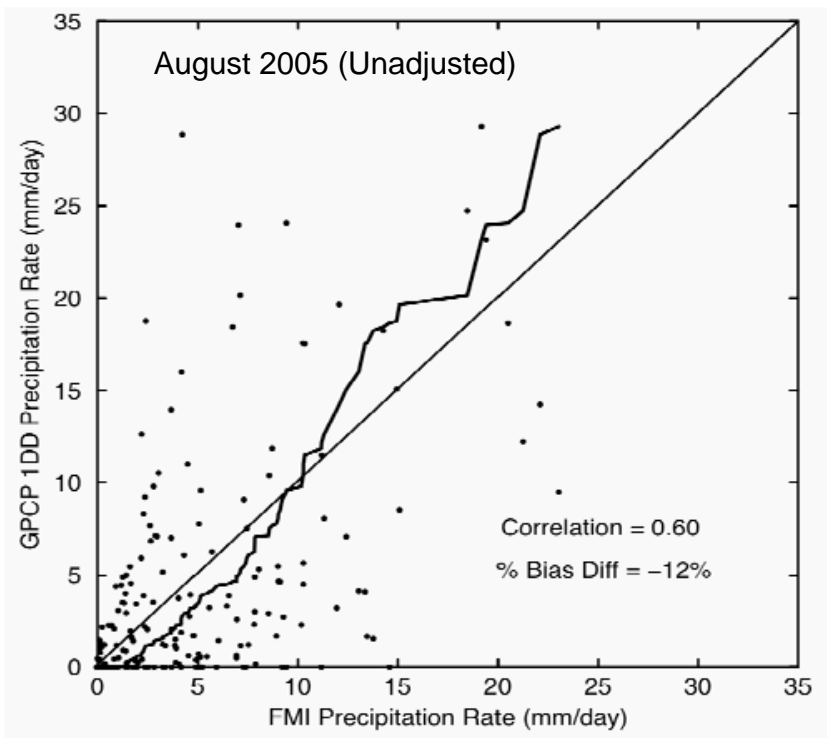

(a)

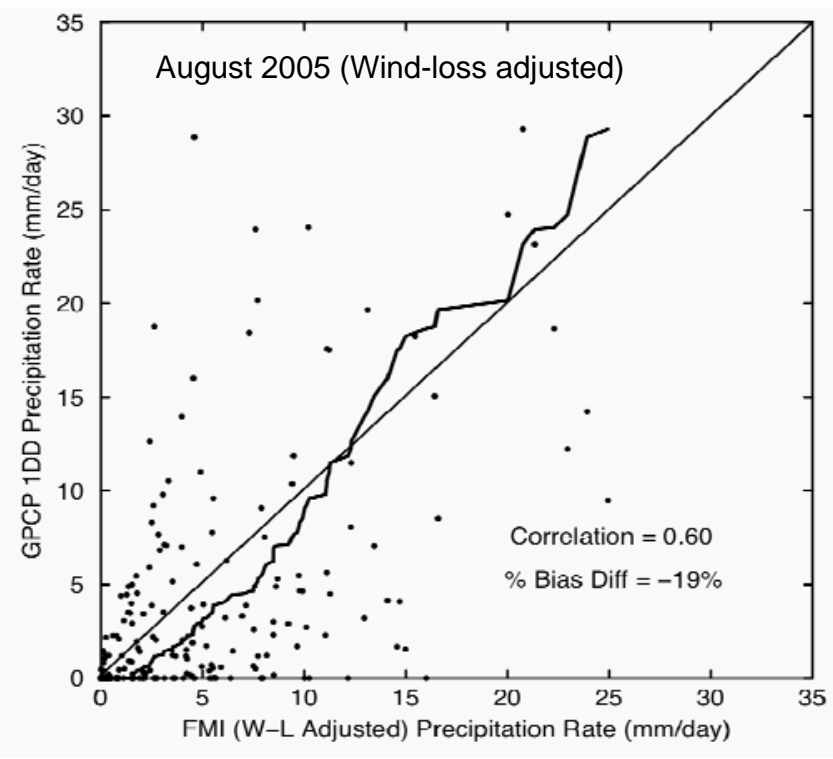

(b)

Fig 9. Scatter plot of all daily $1^{\circ}$ lat. $\mathrm{x} 2^{\circ}$ long. grid box GPCP precipitation estimates and FMI gauge observations, and GPCP estimates and wind-loss adjusted FMI gauge observations from boxes '1'-'8' for August 2005 (Figs. 9a and 9b, respectively). The PDF for each scatter plot is provided (thick line).

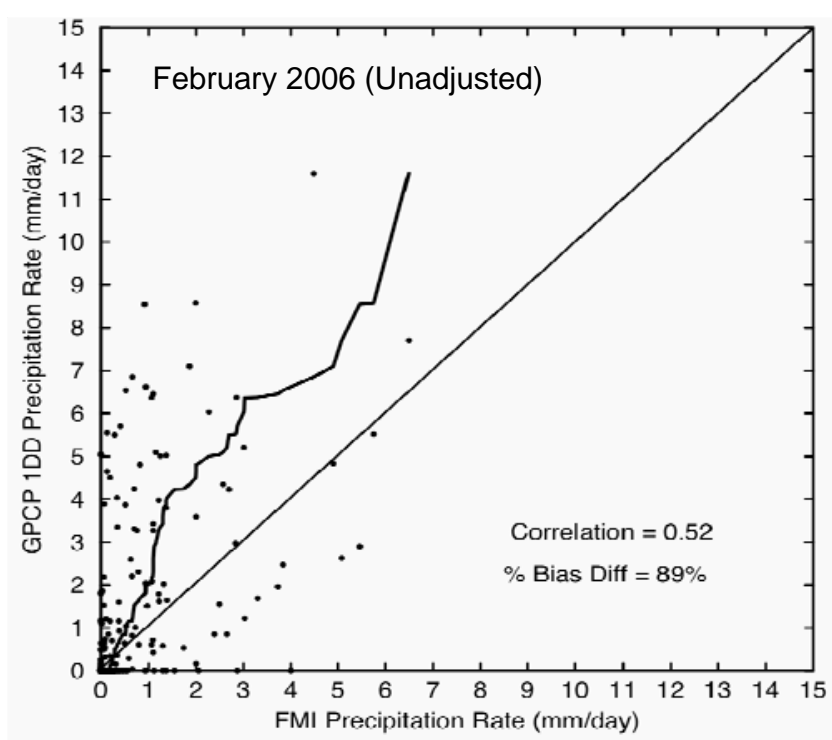

(a)

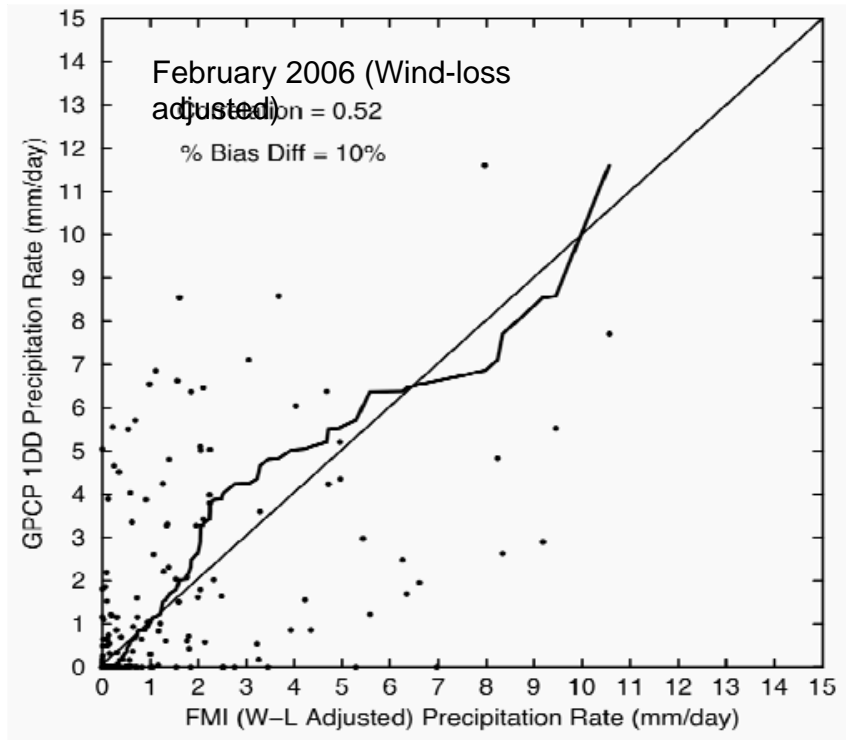

(b)

Fig 10. Scatter plot of all daily $1^{\circ}$ lat. $\mathrm{x} 2^{\circ}$ long. grid box GPCP precipitation estimates and FMI gauge observations, and GPCP estimates and wind-loss adjusted FMI gauge observations from boxes '1'-'8' for February 2006 (Figs. 10a and 10b, respectively). The PDF for each scatter plot is provided (thick line). 


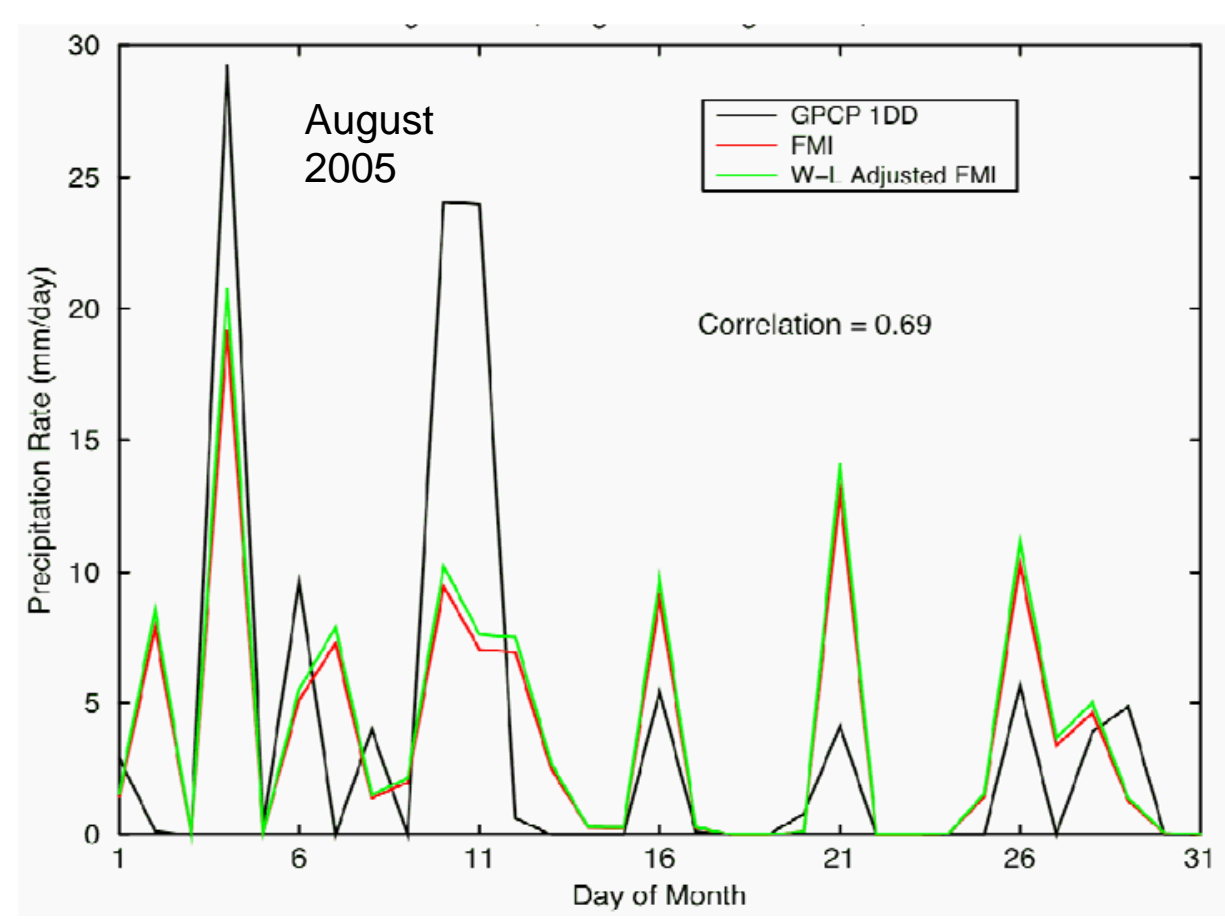

(a)

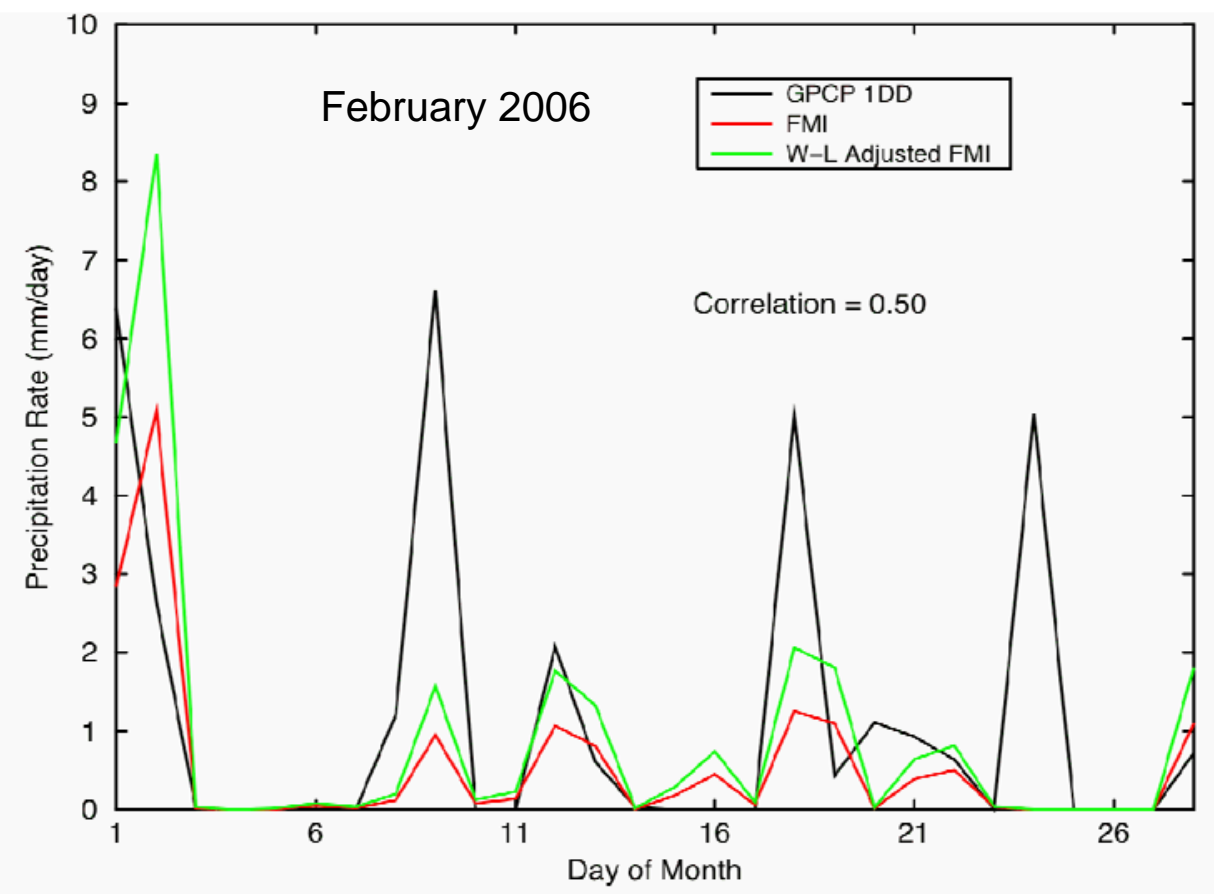

(b)

Fig 11. Time series of daily precipitation of the GPCP (black), FMI (red), and wind-loss adjusted FMI (green) precipitation for August 2005 (Fig 11a) and February 2006 (Fig. 11b) for $1^{\circ}$ lat. x $2^{\circ}$ long. grid box ' 5 '. 


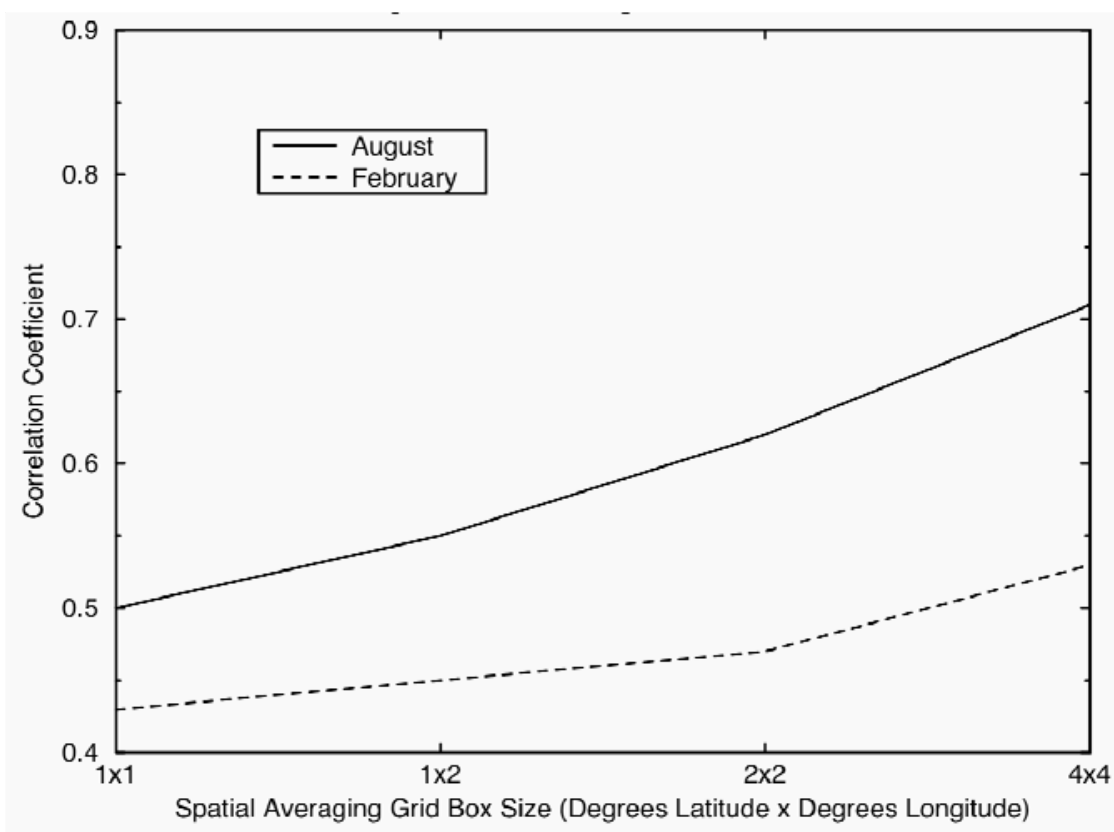

(a)

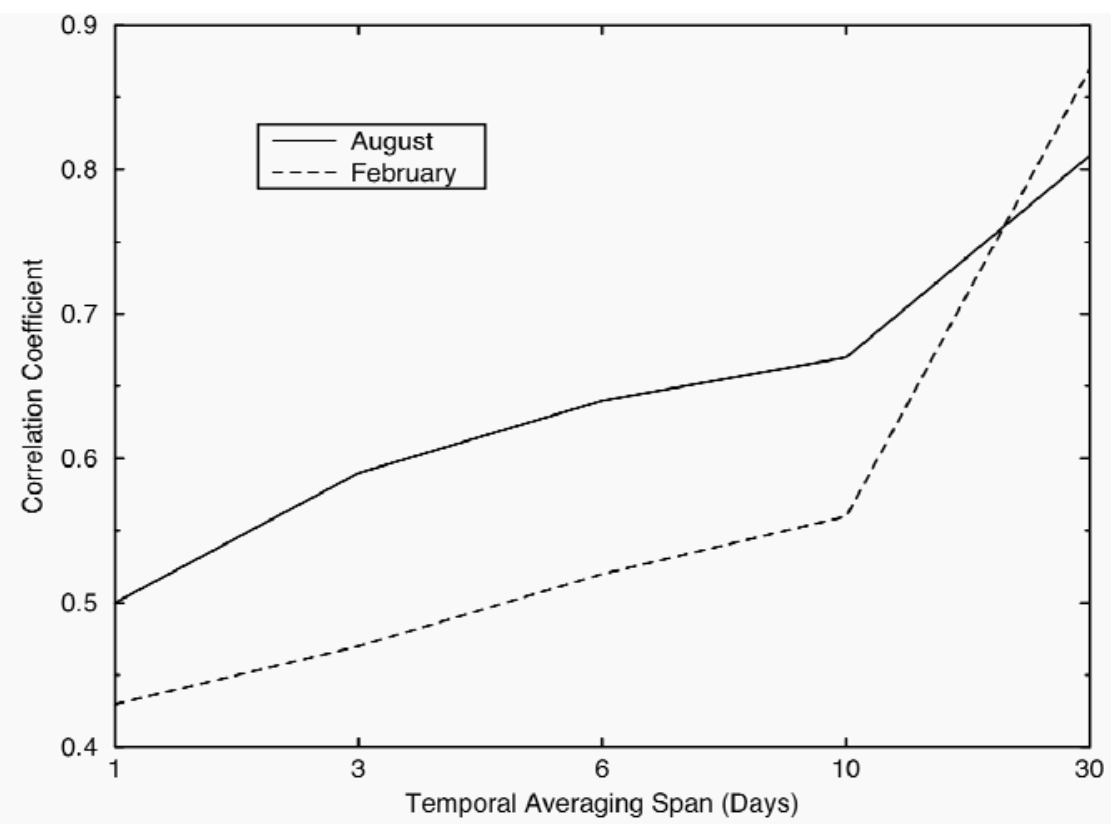

(b)

Fig 12. Correlation coefficient between the daily GPCP and FMI precipitation as a function of spatial averaging grid box size using all Augusts (black) and all Februaries (red) in the entire analysis span 1995 2007 (Fig. 12a), and correlation coefficient as a function of time averaging for all Augusts (solid line) and all Februaries (dashed line) using all $1^{\circ}$ lat. $\mathrm{x}$ $2^{\circ}$ long. grid boxes '1'-'8' (Fig. 12b). 